\title{
Changing Climate and Changing Behaviour: Perceptions of Powerlessness and the Commons Dilemma
}

\author{
Christopher Aitken
}

Thesis

Environmental Studies 593

2009

A 90 point thesis submitted to Victoria University of Wellington, as partial fulfilment of requirements for the degree of Master of Environmental Studies

School of Geography, Environment and Earth Sciences

Victoria University of Wellington

March, 2009 


\title{
Changing Climate and Changing Behaviour: Perceptions of Powerlessness and the Commons Dilemma
}

\author{
Christopher Aitken
}

\begin{abstract}
Mitigating climate change is recognized as an increasingly urgent task that requires several different methods to achieve. Among these is the need to encourage voluntary behaviour change. Doing so necessitates an understanding of the barriers that prevent behaviour change, including those which are psychological. Among the psychological barriers to change are perceptions of powerlessness and the commons dilemma. This thesis takes a mixed method approach to understand importance of these in relation to both each other and other barriers when taking action to mitigate climate change. Results indicate that individuals do not clearly distinguish climate change from general environmental problems and have a tendency to simplify the issues to that considered to be the singularly most important. Powerlessness and the commons dilemma had been evaluated but not extensively or as specifically applicable to climate change. Powerlessness and the commons dilemma were both found to relate to lower amounts of action on climate change and less importance placed upon climate change in actions. Perceived risk and human influence on climate change were the strongest predictors of action. Results generally support the knowledge-deficit model of behaviour change as being applicable to climate change.
\end{abstract}

Key Words: environmental behaviour, powerlessness, fatalism, commons dilemma, climate change, behaviour change, risk 


\section{Acknowledgements}

Thanks, first and foremost, must go to my supervisors Ralph Chapman and John McClure for getting me to the end of this task with plenty of encouragement and advice. Thank you to Alison Adam-Smith for the invaluable advice and aid getting the focus groups up and running. I must also thank my parents for their support and help all along. Thank you to my partner Stacey, for always being there throughout all of this. Thank you to all my fellow masters students for the talks, quizzes and coffees without which this whole process would have been a lot duller. Finally thank you to Suzanne, Hayley, Lin and Susan for all their work keeping the process running smoothly. 


\section{Contents}

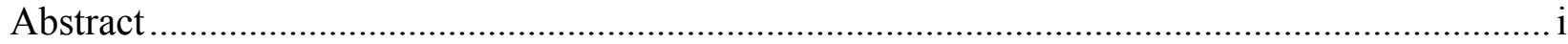

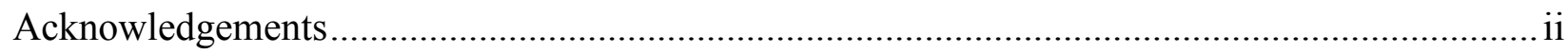

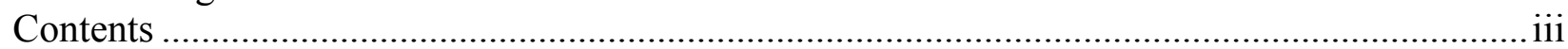

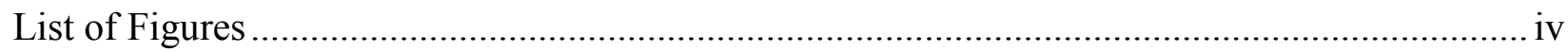

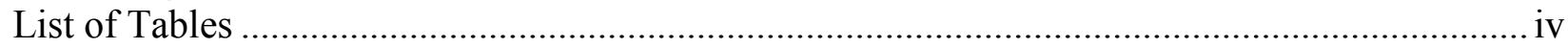

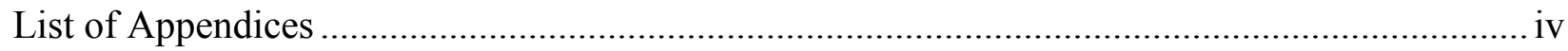

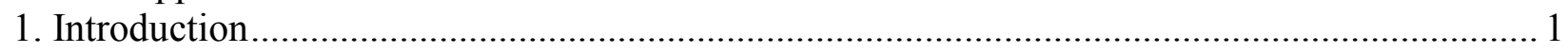

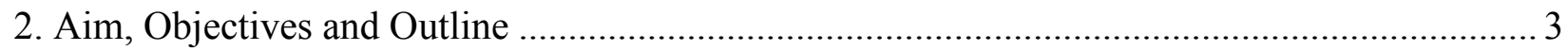

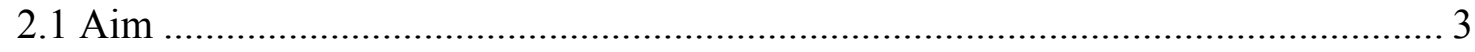

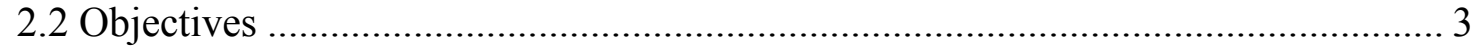

2.3 Outline of Thesis........................................................................................ 3

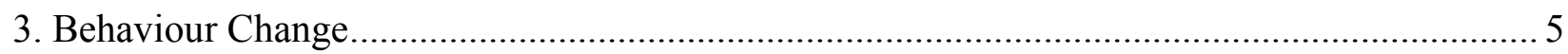

3.1 Pro-environmental Behaviour and Intent........................................................ 5

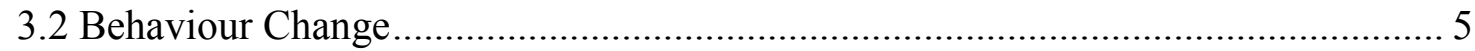

3.3 Regulation and Technological Advance ....................................................... 5

3.4 Voluntary Behaviour Change ......................................................................... 8

3.5 Voluntary Behaviour Change in Combination with Technology and Regulation.... 9

3.6 Barriers to Voluntary Behaviour Change ............................................................ 10

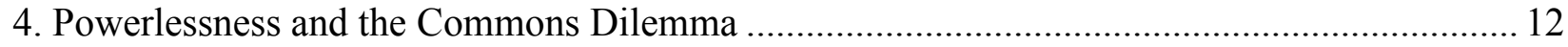

4.1 The Role and Importance of Powerlessness ..................................................... 12

4.2 The Effect of Information on Powerlessness ...................................................... 13

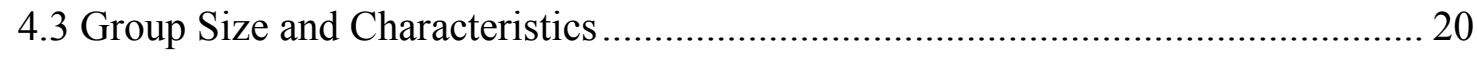

4.4 The Commons Dilemma as Motivation to Not Contribute.................................... 23

4.6 Summary: Powerlessness and the Commons Dilemma..................................... 27

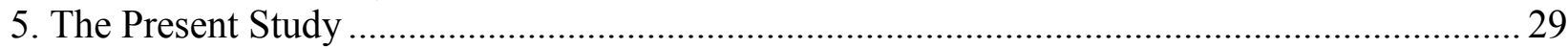

5.1 Gaps in Knowledge and Direction of Research ................................................ 29

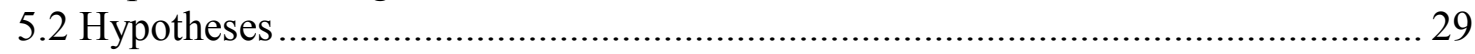

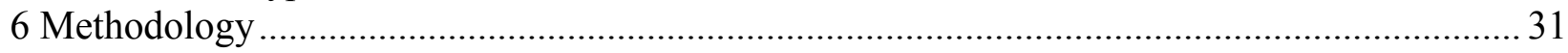

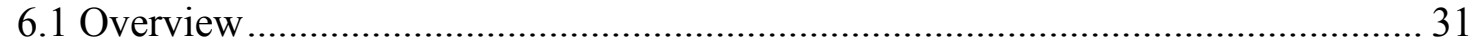

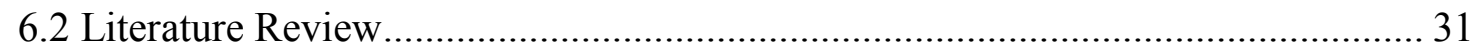

6.3 Focus Groups ............................................................................................ 31

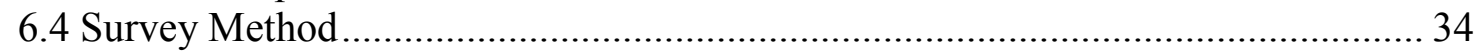

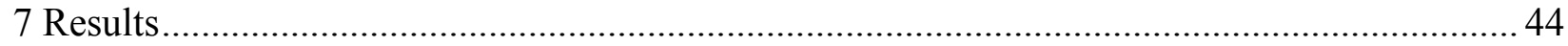

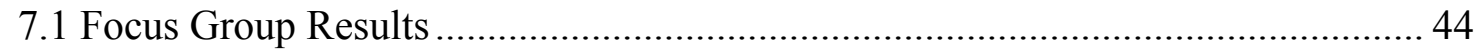

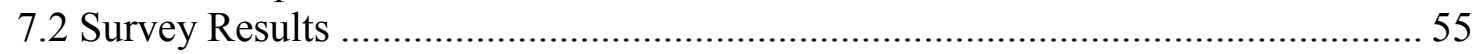

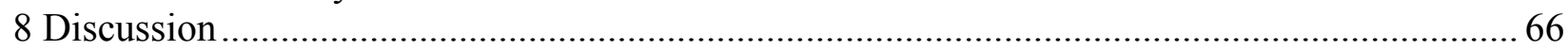

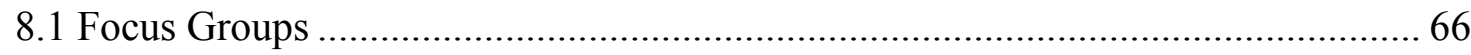

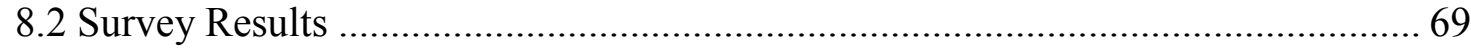

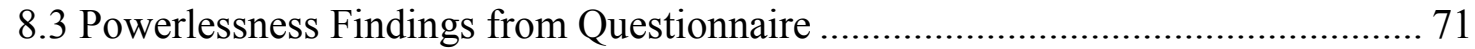

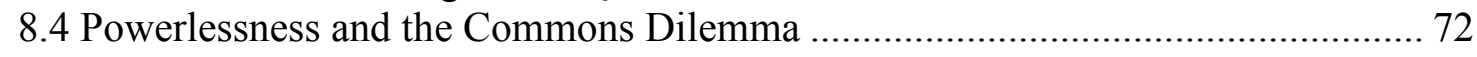

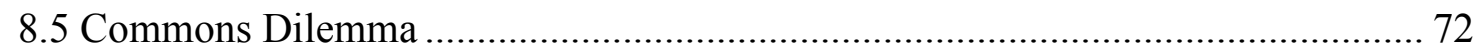

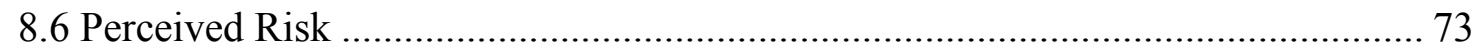

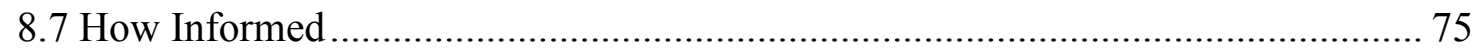

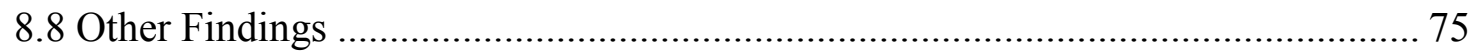

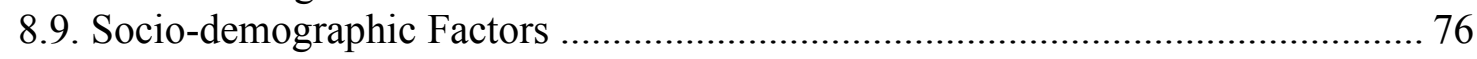


8.10 Results within the Values-Beliefs-Norms Framework ……………………….... 77

8.11 Limitations of this Research ....................................................................... 78

8.12 Directions for Further Research....................................................................... 79

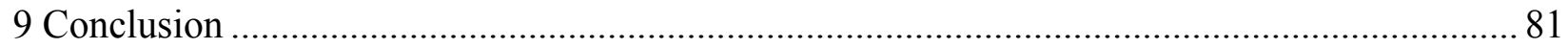

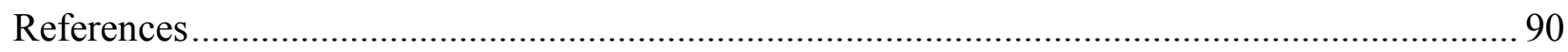

\section{List of Figures}

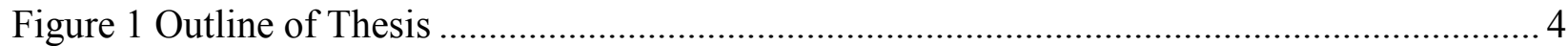

Figure 2 Values Beliefs Norms model of environmental behaviour. Adapted from Stern (2005) 12

Figure 3 Knowledge-Deficit model of behaviour change Adapted from Jackson (2005)............ 14

Figure 4 Summary of information and routes to powerlessness........................................... 19

Figure 5 Dichotomous Climate Change appropriate to criticality ............................................. 22

Figure 6 Continuous climate change appropriate to personal efficacy.................................... 22

Figure 7 Diagram of influences and effects of powerlessness............................................. 27

Figure 8 The Likert scale used for the main body (Questions 7 - 20) of the questionnaire .......... 35

Figure 9 Values Beliefs Norms model of environmental behaviour. Adapted from Stern (2005) 77

\section{List of Tables}

Table 1 Socio-demographics of census areas where focus groups were held from 2006 Census

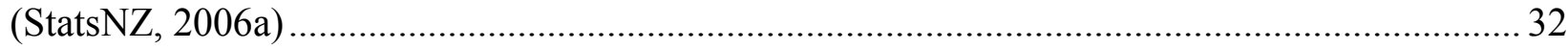

Table 2 Socio-demographics of survey areas from 2006 Census (StatsNZ, 2006a) .................. 43

Table 3 Comparisons of socio-demographics from survey and census (StatsNZ, 2006b) ........... 55

Table 4 Results of Survey Questions 1 -6........................................................................ 57

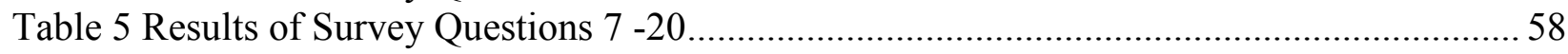

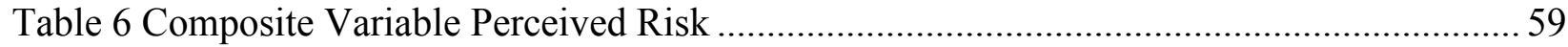

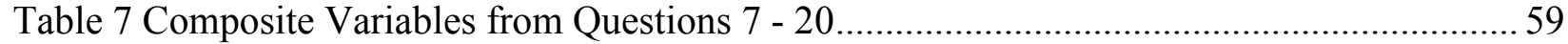

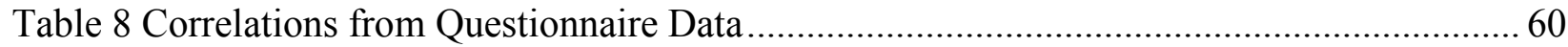

Table 9 Simultaneous Regression Analysis for Socio-demographic and Other Factors predicting

Taking Action .............................................................................................................. 64

Table 10 Simultaneous Regression Analysis for Socio-demographic and Other Factors predicting

Importance of Climate Change in Actions Taken ................................................................. 64

Table 11 Simultaneous Regression Analysis for Socio-demographic, Background and Influence

Rating Variables Predicting rating of Powerlessness ......................................................... 65

Table 12 Simultaneous Regression Analysis for Socio-demographic, Background and Influence

Rating Variables Predicting rating of Commons Dilemma ....................................................... 65

\section{List of Appendices}

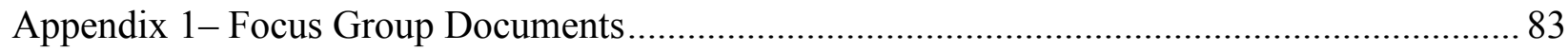

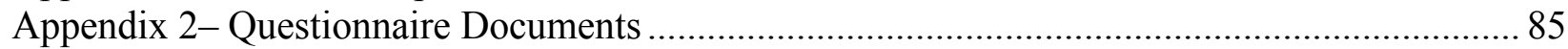




\section{Introduction}

A wicked problem is one which has no clear or easy solution, and also involves uncertainties and the need for change across many levels of society (Rittel \& Webber, 1973). Climate change is considered by many a wicked problem (Eliot et al., 1999; Ludwig, 2001). This is particularly apparent in the way in which it is pervasive throughout all activities of the economy from extraction and production to consumption and disposal. This is unlike almost any other environmental problem before, given that the largest of these have typically been at either sub-global scales or by contrast the result of a relatively small number of outputs, products or processes. Climate change differs from other environmental problems because it is influenced significantly by increases in $\mathrm{CO}_{2}$ and other greenhouse gases that are emitted by a wide range of human activities (Hegerl et al., 2007) and is a very long-lived problem with significant proportions of some of those greenhouse gases remaining in the atmosphere for thousands of years (Solomon et al., 2009). These activities range from many forms of electricity generation (Sims et al., 2003) to the use of automobiles for transportation (He et al., 2005) as well as resulting from other processes such as deforestation (Fearnside \& Laurance, 2004). The ties with energy generation in particular mean that the problem is connected to a huge number of the day to day actions that we, as individuals, take. This adds up to a society-wide problem which will require many changes to the way individuals, households and organisations behave in order for it to be lessened and ultimately solved.

The solution to climate change will depend on many different possible contributions that are offered by different people or groups. As would be expected with such a widespread and diversely generated problem, the possible solutions also vary widely in both method and scale. The scale ranges from individual actions through to nation based approaches. The suggested methods by which changes might occur range from a laissez faire approach, leaving all changes or adaptations to the market's 'invisible hand' as actors in the economy seek to maximise utility or profits (Greenspan, 2007), to a wide-ranging state-enforced reshaping of society and the economy using regulation to make changes (Monbiot, 2006). It is likely that a solution to climate change will fall in between the two extremes and an increase in pro-environmental behaviour will involve some mix of regulation, technological advances and voluntary behaviour change (Romm, 2008). Therefore understanding each of these options is of importance. At this point in time voluntary behaviour change is probably the least understood. Voluntary behaviour change is 
often frustrated by a sense of powerlessness which may or may not be associated with a perception on people's part that they face a commons dilemma. There is some evidence that these barriers are very important in a climate change context so this thesis examines these. 


\section{Aim, Objectives and Outline}

\subsection{Aim}

To evaluate the importance of and relationships among perceptions of powerlessness and the commons dilemma in relation to climate change. Identify any other related perceptions with strong relationships to climate change mitigating behaviour.

\subsection{Objectives}

1 - Review literature on environmental behaviour focussing on the current understanding of powerlessness, the commons dilemma and related perceptions regarding environmental problems, in particular climate change.

2 - Collect qualitative and quantitative data on perceptions of powerlessness and the commons dilemma in relation to climate change.

3 - Report results and analyse data in relation to hypotheses

4 - Discuss findings about the importance and causes of powerlessness and the common dilemma in relation to climate change 5 - Accept or challenge hypotheses. Draw conclusions on hypotheses

\subsection{Outline of Thesis}

This thesis examines two closely related psychological phenomena, powerlessness and the commons dilemma in relation to climate change. The two phenomena have similar causes, similar effects and interact with each other in such a manner that were this thesis to cover only one, an incomplete picture would be presented. The research, within reason, should be applicable to other similar environmental problems involving the provision of public goods.

This thesis initially covers the available scientific literature on behaviour change in chapter 3. Chapter 4 provides a review of the scientific literature on powerlessness and the commons dilemma in order to understand and inform further research and discussion. Chapter 5 gives an overview of gaps in current understanding and sets out the hypotheses to be tested in the course of this research. The methods of primary data collection are then detailed in chapter 6 . Mixed method data collection was used so there is a summary of both focus group and survey methods. In chapter 7 the results of both methods of data collection are presented. Chapter 8 is 
the discussion of these results and in chapter 9 the conclusions are presented. Chapter 10 covers the limitations of this research and outlines directions for further research.

\begin{tabular}{|c|c|}
\hline $\begin{array}{c}\text { Introduction } \\
\text { Chapters 1 and 2 }\end{array}$ & \\
\hline $\begin{array}{c}\text { Literature review } \\
\text { Chapters 3, 4 and 5 }\end{array}$ & Objective 1 \\
\hline $\begin{array}{c}\text { Data Collection } \\
\text { Chapter 6 }\end{array}$ & Objective 2 \\
\hline $\begin{array}{c}\text { Results Reporting } \\
\text { and Analysis } \\
\text { Chapter 7 }\end{array}$ & Objective 3 \\
\hline $\begin{array}{c}\text { Discussion } \\
\text { Chapter 8 }\end{array}$ & Objective 4 \\
\hline $\begin{array}{c}\text { Conclusion } \\
\text { Chapter 9 }\end{array}$ & Objective 5 \\
\hline
\end{tabular}

Figure 1 Outline of Thesis 


\section{Behaviour Change}

\subsection{Pro-environmental Behaviour and Intent}

Depending upon their attitudes, beliefs and values individuals have pro-environmental intentions. Such intentions are formed at a range of scales but can be broadly defined as a desire to decrease or minimise harm done to the natural environment (Stern, 2000). However, proenvironmental intent does not necessarily lead to pro-environmental behaviour. Intent is one variable amongst a host of others that influence whether or not individuals will carry out proenvironmental behaviours. Pro-environmental behaviours are actions carried out with the intention of benefitting the environment and any solution to climate change will necessarily involve increasing the occurrence of this type of behaviour. There are three key means by which pro-environmental behaviour occurs, is enabled or encouraged by relevant actors. They are regulation, technological advance and voluntary behaviour change. These are now examined in more detail.

\subsection{Behaviour Change}

Behaviour change is any modification to the actions of an individual. In this research behaviour change will refer to modifications to behaviour undertaken with the intent of reducing the contribution of an individual to climate change, unless otherwise specified. This does not mean that all behaviour change will necessarily result in a lessening of impact (Stern, 2000). For this research three broad categories of drivers of behaviour change are considered, based around the means by which behaviour change either occurs or is encouraged.

\subsection{Regulation and Technological Advance}

\subsubsection{Regulation}

Regulation refers to causes of behaviour change based upon legal frameworks. They commonly take the form of a ban on harmful actions or products, or the creation of economic incentives to change such as taxes, fines or subsidies. These types of measures have been used for certain environmental problems in the past with positive results. For instance the Montreal Protocol banned the use of chlorofluorocarbons (CFCs) as a refrigerant and propellant in aerosol cans due to the gases' damaging effects upon the ozone hole. This legislation resulted in a 
levelling off and then decreases of the pollutant (N.O.A.A., 2006). The sulphur dioxide emissions trading scheme set up to curb discharge of that pollutant in the U.S.A. used regulation to implement a market based approach and is regarded as a success following significant reductions in the level of the pollutant in the environment (Burtraw et al., 2005).

$\mathrm{CO}_{2}$ emissions have two key characteristics that make the application of similar measures more difficult than in other cases involving environmentally damaging emissions. These stem from $\mathrm{CO}_{2}$ 's ubiquity as an output of diverse processes throughout the economy. The banning, by regulation, of CFCs was relatively easy due to the ability to replace the harmful gases with more environmentally friendly alternatives, something not able to be done with $\mathrm{CO}_{2}$ due in part to $\mathrm{CO}_{2}$ 's primary role as an output rather than input of industrial processes (EPA, 2008). The U.S.A.'s sulphur dioxide trading scheme involved a comparatively small number of large point source polluters, quite unlike the huge number of dispersed and varied polluters emitting $\mathrm{CO}_{2}$ pervading all stages of the economy from production to consumption. For instance the U.S.A.'s sulphur dioxide trading scheme was comprehensive in its coverage yet only involved approximately 3000 emitters whilst the European Union's non-comprehensive $\mathrm{CO}_{2}$ trading scheme covering only large polluters within the Union encompasses already some 11,000 emitters (Stauffer, 2008).

Assuming that the aforementioned problems of using regulation to reduce emissions of a pollutant with characteristics such as $\mathrm{CO}_{2}$ are overcome, there still remain other issues with the method. Regulation, particularly which penalises or prohibits certain behaviours, is often inefficient or undesirable from an economic perspective. This is because bans often limit innovation (Hemmelskamp, 1997) or lead to behaviour that represents an inefficient use of resources. This occurs, for example, when fishing is limited by means of a season. Fishing vessels lie at anchor unused for most of the year and harvest very intensively during the season (Waters, 1991). Furthermore, regulation of this type can lead to significant opposition, making it difficult for political agents to put the plan into action under a democratic system, especially if that system allows for effective protest by concerned groups. The New Zealand government's proposed 2003 methane tax (labelled a fart tax by opponents) is an example of a proposed regulatory solution effectively blocked by protest (TVNZ, 2003). Even if enacted, unpopularity can undermine implementation of a policy. Again, the New Zealand government provides an example with the Emissions Trading Scheme, whose implementation, at least in regard to liquid 
fuels, was delayed following rises in petrol costs (Ministry-for-Environment, 2008). Unpopularity of regulation is particularly important in a liberal market economy; extensive use of regulation can generate widespread resistance due to perceived government intrusion in people's lives.

The effectiveness of economic incentive based regulation, including taxes, subsidies and permits is also limited because decisions about environmentally harmful behaviour are not made in a social and cultural vacuum in which only economic considerations matter (Hinchliffe, 1996). These methods only act on one part of the motivations that determine individuals' behaviour.

Regulation therefore has a number of potential drawbacks. It may be ineffective or impractical to implement in relation to climate change. Even if these drawbacks are addressed it may still be inefficient. In a democratic system regulation can raise opposition that even if limited in scope can be very vocal and consequently make certain measures hard to enact. This does not mean regulation must be discarded entirely but merely that faith in it alone to find or foster a solution is not well placed. However if the public response is inadequate over time to deal with the worsening problem of climate change, regulation is likely to become increasingly necessary in order to implement a rapid solution.

\subsubsection{Technological Advance}

Technological advance refers to change in behaviour as a result of improvements in the available methods and equipment used to carry out actions. These encompass changes from a certain action to another, for instance improvements in internet capabilities allowing the use of telecommunications to 'attend' a conference as opposed to travelling to it, resulting in a decrease in emissions due to lowered energy use. Or it can refer to changes in the way an action is carried out, for instance gains in efficiency which allow a manufacturing process to be carried out with less total energy input.

When dealing with technological advance as a solution to climate change it is important to distinguish between views of technological advance as being the solution and viewing it as part of the solution. When technological advance is advocated as the solution it usually implies a laissez faire approach that relies on improvements in science and technologies of production to produce goods and services more energy efficiently and cleanly, thus reducing the environmental harm, or a reliance on future technologies such as a system to capture greenhouse gases from the atmosphere or cloud seeding and so on. Relying on this is based on the assumption that both 
consumers and producers search for and create the most efficient technology in order to reduce costs and/or maximise profits and that this is sufficient to reduce emissions to a desired level. A high profile example of technological advance involving reductions in $\mathrm{CO}_{2}$ emissions is the popularity of 'hybrid' vehicles such as the Toyota Prius in recent years.

However this approach is beset with problems. For instance despite huge gains in efficiency in the relevant technologies over the previous century, $\mathrm{CO}_{2}$ emissions have continued to climb (Marland et al., 2007). This is because growth in demand often outstrips or at best offsets gains in efficiency rather than actually resulting in a lowering of net emissions (Brookes, 1990; Schipper \& Grubb, 2000). At the level of the individual consumer the rebound effect reduces the potential value of this solution (Binswanger, 2001; Greening et al., 2000). This occurs when individuals make monetary savings due to efficiency, for example, saving on petrol per kilometre due to increased fuel economy of a new vehicle, but negate or decrease those gains by increasing consumption, for example driving further or spending the extra money on other activities that result in further emissions.

Using technological advance as part of the solution however is quite different. This is the notion that gains in efficiency are welcome but that they alone cannot act as a solution to climate change; instead technological advance must act alongside regulation (Brown et al., 1998) and voluntary behaviour change with the latter two also acting as drivers of advances in technology.

\subsection{Voluntary Behaviour Change}

In the context of this research 'voluntary' refers to behaviour change being undertaken of the individual's own accord without the use of regulation to either constrain behaviour or provide economic incentives. This does not mean that economic incentives to change do not exist. But rather that those incentives exist because, for instance, new technology is cheaper due to lower running costs from greater energy efficiency as opposed to being cheaper due to subsidies or taxes reducing the economic appeal of alternatives. This draws one to the need to distinguish voluntary behaviour change and technological advance. Both are described as voluntary in the sense that they are not inherently encouraged or required by legislative means. However technological advance covers only one aspect of change, that of taking up more efficient equipment and methods. Voluntary behaviour change however is much broader in scope. It covers not only the adoption of aforementioned technological changes but also changes from one 
behaviour to another e.g. travelling by bus instead of a car to work, reducing some activities e.g. taking shorter showers and ceasing certain behaviours altogether e.g. international air travel. None of these examples should be considered technological advances.

Voluntary behaviour change is a solution that in principle applies to both organisations and individuals, but in practice is most relevant at the micro level i.e. individuals and households. Voluntary behaviour change might be most effective with such low level and dispersed emitters of $\mathrm{CO}_{2}$ because of the relatively high initial expense of technological solutions in contrast to the availability and low cost of simple possibilities for change. Technological advance however is likely to be more appropriate for large point source emitters, e.g. industry such as electricity generation, for which a large expense associated with an upgrade such as emissions scrubbers is possible and voluntary change such as running generators for shorter periods is not an option, or at best, unlikely to take place.

Common examples of voluntary behaviour change at the individual and household levels include switching from a standard electricity retailer to a 'green' one or taking public transport to work instead of driving a car, both of which lower energy demands and subsequently carbon dioxide emissions.

\subsection{Voluntary Behaviour Change in Combination with Technology and Regulation}

As with technological change it is naive to consider voluntary behaviour change capable of modifying all behaviour that affects climate change to sustainable patterns. Instead it must play an important role alongside technological advances and legislative measures as a solution to climate change. When coupled with technological advance, it can encourage the adoption of better technology, especially when economic incentives to change are weak or non-existent and help to prevent or reduce the rebound effect once change does occur. Voluntary behaviour change is seen as both complementary to and as an alternative to regulation. It is complementary in a few situations. For one, it can show politicians and the business sector that there is support for measures to address climate change and thus act as a precursor to legislative action otherwise considered too radical to enact, or enable 'green' ventures to become commercially viable due to an increase in demand for the product or service without the need for taxes or some other incentive. If successful in a particular endeavour, voluntary behaviour change can reduce the necessity for regulation by achieving a similar outcome to some law changes. 
A combination of the three approaches to change will be likely to achieve the best results. Behaviours are determined by a range of factors, not for instance just those which are economic (Hinchliffe, 1996); so focussing on just one set of measures is likely to reduce the effectiveness of any implementation strategy aimed at bringing about a change of behaviour. This means that encouraging voluntary behaviour change requires a focus on all levels and types of motivations behind behaviour (Lucas et al., 2008). In particular psychological factors should be recognised as important (Leiserowitz, 2006; Stehr, 1997) and measures to address them must act in a complementary manner to other means of encouraging change (Jackson, 2005).

A reliance on methods centred on economic motivations acts to strengthen those factors in the minds of individuals and may increase the difficulty of using other methods to encourage behaviour change (Hinchliffe, 1996). This must add a sense of urgency to the task of finding and implementing solutions that use well judged combinations of approaches.

\subsection{Barriers to Voluntary Behaviour Change}

Modifying behaviour can be beneficial for the environment and thus society but change often does not occur among individuals of their own accord (Dawes \& Messick, 2000). Even when there are co-benefits and people are aware of a social norm in which they 'should' choose an environmentally beneficial behaviour, they often continue to act in the usual or default manner (Pichert \& Katsikopoulos, 2008). The reasons for such behaviour fall into a number of categories that include financial cost (Stern, 1999), lack of alternatives (Stanbridge et al., 2004), anticipated regret (Anderson, 2003), inconvenience (Stern, 1999), ignorance (Bulkeley, 2000; Wallace, 1994), lack of concern (Semenza et al., 2008), laziness or habits (Stanbridge et al., 2004), the commons dilemma (Dawes \& Messick, 2000) and perceptions that their contribution can make no difference, i.e. powerlessness (Jackson, 2005; Lorenzoni et al., 2007). This research will focus on the last two, the commons dilemma and powerlessness.

Even when the reasons for not changing listed above are not compelling, voluntary behaviour changes, like other methods of reducing environmental impact, is subject to the rebound effect (Binswanger, 2001). For example individuals might replace their incandescent light bulbs with more efficient compact fluorescent light bulbs but no longer be concerned about switching them off when not needed. While this can still result in a lessening of energy use part of the potential gain is lost. 
These effects mean that sufficient voluntary behaviour change is unlikely to occur amongst individuals of their own accord. Instead it is something that must be encouraged and supported through means such as third party campaigns. Examples of these include the 'Helping the Earth Begins at Home' campaign run by the British government in the 1990's and the 'Be the Difference' campaign run by the Greater Wellington regional council in the 2000's. Without these types of measures individuals are unlikely to modify their actions due to the many potential reasons for inaction that can be encountered (Jackson, 2005). But encouraging behavioural change is a complex process in which individuals rarely act on information about causes and effects alone. A wide range of other psychological and cognitive factors has been shown to play an important role in deciding whether and how individuals respond to climate change and under some circumstances to predict behaviour better than any considerations of society or economics (Grothmann \& Patt, 2005). Psychological and cognitive factors can either encourage change or inhibit it and act as barriers to change. Climate change is no exception and it is subject to a wide range of mental barriers (Harré, 2007). In order for campaigns aiming to change behaviour to be most effective they must address specific barriers to change (Jackson, 2005). Overcoming these barriers will require careful design and a thorough understanding of their causes and effects. 


\section{Powerlessness and the Commons Dilemma}

\subsection{The Role and Importance of Powerlessness}

Within the topic of behaviour, powerlessness is a term that covers two different aspects in two different models. Ajzen's (1991) Theory of Planned Behaviour uses powerlessness to refer to the perceptions that individuals have about their level of control over their actions. That is, is an individual free to choose any option or are they forced to choose a particular one? Stern's (2000) Values-Beliefs-Norms theory of behaviour also includes powerlessness. However in this model it has a different meaning, referring to perceptions of being powerless to affect an outcome by taking action. That is, will taking action make some difference to the relevant result?

This research will examine powerlessness as defined in Stern's (2000) model, perceptions of powerlessness over results. Specifically, in relation to climate change, powerlessness is the perception amongst individuals that the contribution from changing their own behaviour cannot have any impact upon either whether climate change occurs or the degree of change.

Powerlessness of this nature is also commonly referred to as helplessness or fatalism. This perception is an important barrier to behaviour change because individuals who consider themselves powerless to affect the outcome of an environmental problem have lowered motivation to make sacrifices to mitigate the issue (Haller \& Hadler, 2008). There are typically three main causes of powerlessness; these are information, confusion and the commons dilemma.

Individuals' feelings of powerlessness occupy an important position within the determination of pro-environmental behaviours and thus are considered to be a critical potential barrier to overcome. Evidence of this is found in the prominent position of powerlessness in one of the chief theories used today to explain environmental behaviour. This is the Values-BeliefsNorms theory, powerlessness forms Step 2c in Figure 2 below.

\begin{tabular}{|c|c|c|c|c|c|}
\hline Values & \multicolumn{3}{|l|}{ Beliefs } & $\begin{array}{l}\text { Proenvironmental } \\
\text { Personal Norms }\end{array}$ & Behaviours \\
\hline Biospheric & Ecological & Adverse & Perceived & Sense of & $\rightarrow$ Activism \\
\hline \begin{tabular}{|l|} 
Altruistic \\
Egoistic \\
\end{tabular} & $a$ & $\begin{array}{l}\text { Consequences } \\
\text { for valued } \\
\text { objects }\end{array}$ & $\begin{array}{l}\text { ability to } \\
\text { reduce } \\
\text { threat } \\
\text { /Powerlessness }\end{array}$ & \begin{tabular}{|l|} 
obligation to \\
take proenviron- \\
mental actions
\end{tabular} & \begin{tabular}{|l|} 
Non-activist \\
public sphere \\
behaviours
\end{tabular} \\
\hline & & & & & $\begin{array}{l}\text { Private-sphere } \\
\text { behaviours }\end{array}$ \\
\hline $\begin{array}{l}\text { Step } \\
1\end{array}$ & $2 a$ & $2 b$ & $2 c$ & 3 & $\begin{array}{l}\text { Behaviours in } \\
\text { organisations }\end{array}$ \\
\hline
\end{tabular}

Figure 2 Values Beliefs Norms model of environmental behaviour. Adapted from Stern (2005) 
Within the Values-Beliefs-Norms theory of behaviour, values are defined as relatively stable characteristics of an individual's personality; beliefs are more specific and can vary much more widely both between issues and over time; norms are derived from society and tend to be activated when, for example, beliefs that the environment is threatened and the individual can have an influence on this are present; and behaviours covers the various actions the individuals might take with pro-environmental intent (Stern, 2000). Powerlessness fits into this theory as an influential belief at one end of the spectrum of beliefs about one's ability to reduce threats. As such, it is a belief that must be understood well in order to design effective communications on the topic of behaviour change.

Experimental data backs up the importance of powerlessness as a predictor of proenvironmental intentions. Research has shown that people who are fatalistic regarding environmental issues have low levels of willingness to pay for environmental protection ( $r=$ $0.455^{*}$ ) (Haller \& Hadler, 2008). The implication of this study is that those who are more powerless are less likely to take pro-environmental action. This study incorporated survey data from multiple countries.

These results suggest placing powerlessness in a key position as a predictor of environmental behaviours. Based on this, it is expected that powerlessness regarding the ability to affect climate change will reduce the willingness of individuals to make changes that bear some cost, be it financial or otherwise e.g. inconvenience or time.

\subsection{The Effect of Information on Powerlessness}

\subsubsection{Overview}

The Knowledge-Deficit (also termed Information-Deficit or Persuasion Theory) model of behaviour change underlies many communications to encourage behaviour change (Barr \& Gilg, 2007; Barr et al., 2001). At the core of this idea is the notion that individuals, when informed sufficiently on the causes, consequences and risks associated with a particular behaviour, modify their actions accordingly (Hansen et al., 2003).

When the Knowledge-Deficit model is applied to environmental issues it typically means providing the target audience with information to indicate the severity of the problem. The presumption is that once informed of the need and urgency for action the attitude of individuals will be modified, in turn leading them to change their behaviour. This process is illustrated in 
Figure 3 below. Individuals are first given general information on a topic. Having understood this they are next provided with more specific details until the problem and potential solutions become 'common knowledge'. Following this it is expected that their attitude towards a given action is modified and finally in turn behaviour is also modified to a more pro-environmental course of action.

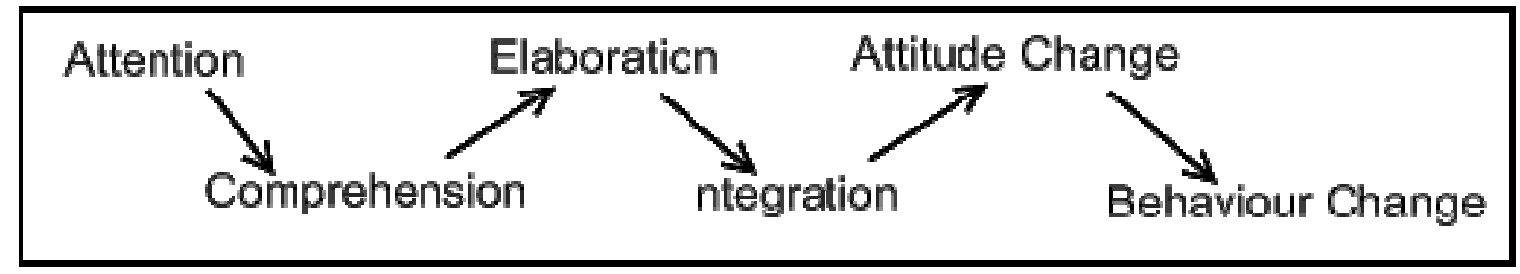

Figure 3 Knowledge-Deficit model of behaviour change Adapted from Jackson (2005)

The Knowledge-Deficit model, as applied to general environmental problems, has some support from empirical findings. General knowledge of the environment and human interactions with it has been shown to correlate moderately with diminished feelings of fatalism and to a lesser degree with willingness to make sacrifices for environmental protection (Haller \& Hadler, 2008). Similarly a high level of media attention given to environmental problems has been found to correlate positively with high levels of concern about environmental problems in the general public (Harrison et al., 1996). At the same time this coverage was found to lead to a sense of too many issues 'beyond the power and capacity of people to deal with' (Harrison et al., 1996) i.e. an increase in powerlessness. However a subsequent decline in news coverage led to an increase in cynicism and doubt about the validity of claims about environmental problems (Harrison et al., 1996). However it must be noted that in both of these cases it is general knowledge of the environment as opposed to specific knowledge regarding any particular environmental issue.

Messages aiming to influence individuals to change behaviour for reasons relating to climate change appear to be similarly motivated by a Knowledge-Deficit model and many campaigns with this aim have been shaped by this model (Barr \& Gilg, 2007; Potter \& Oster, 2008). For instance the popular movie An Inconvenient Truth takes this approach by presenting viewers with a large amount of information on the science of climate change (Kellstedt et al., 2008; Potter \& Oster, 2008).

The actual effect of giving further information may be quite different from that desired. There is strong evidence suggesting that supplying more information about environmental problems to individuals is unlikely to result in a change to their behaviour despite increases in 
intentions to change behaviour (Barr \& Gilg, 2007). Multiple factors are responsible for determining whether increased knowledge about a subject leads to increased action on the matter also. Among these factors, powerlessness is known to be influential to behaviour (Haller \& Hadler, 2008); therefore any influence that information has upon powerlessness is of interest to those trying to change behaviour using an information based approach.

There have been multiple studies of the effect of levels of information, in terms of both quality and quantity, on levels of powerlessness. These have covered both general environmental problems and the specific issue of climate change. Results are conflicting. One study found that the greatest predictor of taking action and/or supporting legislation to mitigate climate change is a correct understanding of the mechanisms and causes of it (Bord et al., 2000). This finding provides support for a Knowledge-Deficit model of behaviour change and is in line with the findings of Haller and Hadler (2008) about knowledge, fatalism and general environmental problems.

Directly contrasting with the findings of Bord et al. (2000) are the results of another study. This study has found that when individuals have greater knowledge and certainty about the science of climate change, they show decreased levels of concern towards the problem (Kellstedt et al., 2008). The expected result of this is that individuals will take less action or show less support for climate change mitigation measures. Decreased concern about the risks associated with an environmental problem has been demonstrated to lead to higher levels of fatalism and lower levels of willingness to sacrifice (Bord et al., 2000; Haller \& Hadler, 2008). Exactly why individuals should exhibit lowered concern about climate change when they have greater knowledge of the science, as indicated by Kellstedt et al. (2008), which runs contrary to the Knowledge-Deficit model, is unknown. A clue to a possible explanation is that '[f] acts do not determine behaviour so much as perceptions about facts '(Niemeyer et al., 2005). Powerlessness is likely to be one of those perceptions. Powerlessness resulting from information might in turn be due, primarily to a combination of two factors, the scale of climate change and uncertainty.

\subsubsection{Information on the Scale of Climate Change}

Powerlessness often appears to arise in relation to the nature of information regarding climate change (Jackson, 2005). When information presents an impression of climate change in which it is severe or difficult to mitigate, as may occur when messages raising awareness of the 
issue focus upon catastrophic effects, powerlessness is a plausible reaction amongst individuals. Catastrophic effects frequently attributed to climate change in the media include increasing numbers or severity of hurricanes (Moss, 2009), melting polar ice caps (McKie, 2009) and rising sea levels (Wood, 2009). Such physical effects all take place at scales which are at least regional and often global. At either of these levels the problem and potential solution are beyond the scope of an individual to deal with and indeed, even to comprehend (Nicholson-Cole, 2005). This can lead to confusion (examined in greater detail in the next section) or a feeling of being just a 'drop in the ocean' when compared to the global response that such problems necessitate (Lorenzoni et al., 2007). Additionally, a more direct result of information about catastrophic effects is the apparent disconnect between the huge problem and the small individual actions possible and frequently called for by proenvironmental campaigns. For instance in the face of such huge and apparently overwhelming effects as devastating drought, the potential for one person to prevent or even influence them, by means of, for example, turning off a stereo, seems very slim (Stoll-Kleemann et al., 2001).

Niemeyer et al. (2005) provide some evidence for a relationship between information and powerlessness in which information contributes to a raised level of powerlessness. Individuals were presented with different scenarios of climate change. The more severe the impacts of climate change, the more individuals believed adaptation was unlikely to occur and the effects of climate change were inevitable, this represents an increase in powerlessness. Furthermore as the perceived difficulty of mitigation of an environmental issue increases the likelihood of an individual taking action decreases (Green-Demers et al., 1997). Thus information that fosters perceptions of climate change as a huge problem may contribute to feelings of powerlessness and an acceptance that the consequences of climate change will be the same regardless of their contribution. Powerlessness of this nature, as influenced by messages, is well documented in response to earthquakes when messages focus upon the most severe effects (McClure et al., 2007).

\subsubsection{The Role of Uncertainty}

Information on the scale of the issue is not the only way in which messages on climate change contribute to powerlessness. When conflicts between norms occur, individuals often fall 
back on powerlessness as an excuse for avoiding a decision on the issue (Schwartz \& Howard, 1981). It seems likely that this also occurs when there are conflicts regarding information. In order to understand how uncertainty causes powerlessness and inaction it is necessary to draw upon several different theories. The appropriateness framework (Weber et al., 2004) provides a starting point. This framework suggests that individuals in commons dilemma situations, like climate change, make decisions by asking themselves "What does a person like me do in a situation like this?" In order to answer this question, individuals must be able to both identify the situation and identify the typical or expected responses, that is, norms. Climate change presents a case in which both the situation and the typical response of others is hard to predict. Assessments of the situation are difficult for the public. Gauging the reality and severity of climate change is difficult when the messages they receive through the mainstream media portray far greater uncertainty about the issue than is present within the scientific community (Boykoff \& Boykoff, 2004; Lorenzoni et al., 2007). Assessing the typical response of others is increasingly difficult as the number of individuals and/or the temporal scale increases (Kortenkamp \& Moore, 2006). Climate change is made difficult to assess by its nature regarding both of these factors. Firstly the time frame of climate change is not one that is conducive to building a clear picture of the response of others due to the differences in meaning between long term for the climate and long term for the individual. A study in the United States found that when individuals were asked about 'the future' they thought of a time 10-15 years ahead (Tonn et al., 2006). Certainly this kind of timeframe is inadequate when dealing with climate change due to the greater length of time over which it occurs and the many lags involved (Moser \& Dilling, 2004). Secondly climate change is also a global problem which affects individuals the world over; this makes assessing the response of others much more difficult, if not impossible, due to the huge number of variables present. With inability to identify the situation and/or the response of others, uncertainty is the result. Raised levels of uncertainty about environmental issues have been found to correspond with lowered levels of cooperation in a commons dilemma (Kortenkamp \& Moore, 2006).

Powerlessness is one pathway by which uncertainty leads to inaction. Uncertainty and disorientation due to a large number of messages, many subtly or significantly conflicting with each other, is identified as a cause of powerlessness about environmental problems (Kaplan, 2000). For individuals who are attempting to create a clear and coherent picture of the issue of 
climate change, this can be overwhelming and they may simply 'give up' on the matter, perhaps by labelling it too big or too poorly understood for effective comprehension. Kaplan goes on to suggest that the reason for this is that individuals 'hate' to feel confused and instead prefer to find a simple way around this such as dismissing the issue by means of defining themselves as powerless and waiting for further information that resolves the conflict. This process can be described as an 'overloading' of information and is consistent with Schwartz and Howard's (1981) theory of how individuals cope with conflicting norms.

An evolutionary perspective offers an underlying explanation for why individuals 'hate' confusion and seek ways to minimise it (Anderson, 2003). When human survival was much more marginal than it is today bad decisions might easily have made the difference between life and death of a group. Therefore avoiding hasty decisions, staying with the status quo and deliberating to arrive at a complete picture would offer an evolutionary advantage. As regards climate change a similar response would mean that individuals wish to stick with the status quo, that is, take no action, until their confusion has been minimised, in the (probably vain) hope that the best possible decision is made.

Figure 4 below presents a summary of the ways in which information about climate change can lead to powerlessness on the part of the individual. This has been formed based on the review of current literature on the topic. 


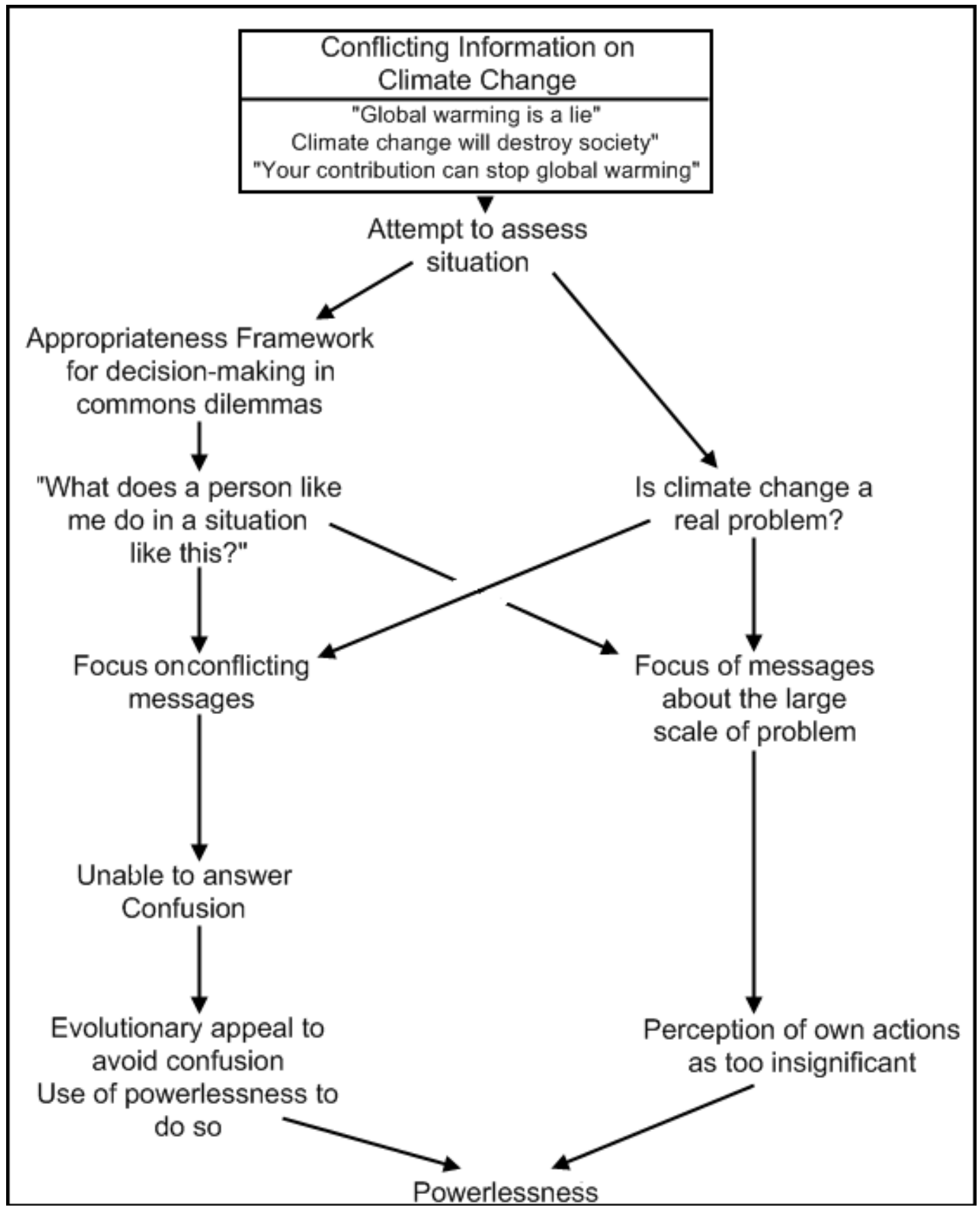

Figure 4 Summary of information and routes to powerlessness

\subsubsection{Uncertainty due to Characteristics Specific to Climate Change}

Climate change has several attributes that make it a topic more likely to create confusion amongst the public than other issues. The nature of climate change is one that is both beyond the everyday experiences of individuals (Harré, 2007) and counter-intuitive to lay perceptions of climate. This has been suggested as a contributor to confusion and powerlessness (Stehr, 1997). 
Among the public there is a general belief that climate (and nature in general) is constant and even. This belief is summed up in statements such as 'The impression that climate is a constant phenomenon is deeply embedded in everyday consciousness and it is manifest in the profound confidence that any unusual seasonal or annual weather pattern must be compensated for in subsequent periods. ' (Bruckner, 1890 cited in Stehr, 1997).

Secondly compared to another atmospheric problem of recent years, the ozone hole, climate change is a difficult problem for a scientifically ill-informed public to grasp (Moser \& Dilling, 2004; Ungar, 2000). The ozone hole can be understood as a relatively simple chain of causes and effects from chlorofluorocarbons to ozone depletion to skin cancer. This enables the public to quickly take on board knowledge of the problem and proceed to some level of support for mitigating it. Climate change on the other hand is a much murkier topic with many causes and effects and uncertainties as well as a long time frame. These factors combine to make the topic much harder for the general public to grasp.

Research into these areas however, is minimal and as yet there is little empirical evidence to support claims that climate change is a topic particularly prone to confusion amongst the lay public.

\subsection{Group Size and Characteristics}

So far this review has covered powerlessness in relation to levels of knowledge, information, confusion and attributes of climate change. A further important consideration is how the individual views their contribution compared with that of the group. When encouraging collective action from a group, theorists such as Olson (1971) expect group size to have a negative relationship with active involvement; i.e. individuals will take less action or show less involvement as the size of a group increases.

With regard to taking actions to reduce contributions to climate change, group size and an individual's significance within the group influence perceptions of powerlessness amongst individuals. The reasons for this are criticality and personal efficacy. It is unclear at this point whether both of these factors are of equal importance or if one overshadows the other. Research needs to be conducted to clarify this. 


\subsubsection{Criticality: Will Each Make a Difference?}

Climate change can be viewed as a public bad (Tsur \& Zemel, 2008) and thus the provision of a stable climate as the provision of a public good. A public good is usually difficult to supply through voluntary behaviours alone (Ostrom \& Ostrom, 1999) (see section 4.4 for more detail). This is especially true when the good crosses international boundaries (Desai, 2003) or has a very large group size (Hindriks \& Pancs, 2002). A stable climate certainly fulfils both of these categories. Difficulty in supplying is due to the nature of public goods, which does not allow for those who do not pay for the good to be excluded from receiving the benefits of its provision. This enables individuals to not pay for a good and still receive the benefits thus creating an incentive to free-ride.

Despite this individuals do still contribute in public good situations (Dawes \& Messick, 2000). Individuals, when assessing whether or not to contribute to a public good, take into account the 'criticality' of their contribution. Criticality is the assessment of whether or not their contribution will be the deciding factor in whether or not a public good is provided. When individuals feel that their actions are critical to the outcome, which is that their contribution will be the deciding factor, they are more likely to be motivated to act on an issue. The reverse, that individuals are less likely to contribute if a public good is provided regardless of their actions, is also true (Cremer \& Dijk, 2002). Whether an individual's contribution is likely to be critical depends largely on the size of the group involved. The effect is such that the likelihood of an individual's contribution being critical decreases as the scale of the public good increases.

Climate change is an issue of such wide scope, both crossing international boundaries and having a global group size, that few, if any, individuals' or even countries' contributions are critical in this direct manner. Thus egoistic individuals are likely to be reluctant to take on a cost to prevent climate change when they judge that the outcome will be the same with or without incurring that cost.

\subsubsection{Personal Efficacy: Will My Contribution Matter?}

The idea of criticality with regard to the provision of a stable climate is not entirely appropriate. It applies most strictly to a public good which has only two possible conditions, fully provided or not provided at all. This is not a valid description of climate change. The problem does not show a 'clear line' between a fluctuating or altered climate system causing harm on one hand (see Figure 5) and a stable climate bringing benefits on the other. Instead there 
is a continuum of varying degrees of effect (see Figure 6). Thus it is more appropriate to examine individuals' perceptions of powerlessness in relation to their assessment of how much they feel able to influence the degree of climate change rather than the outright occurrence of climate change.

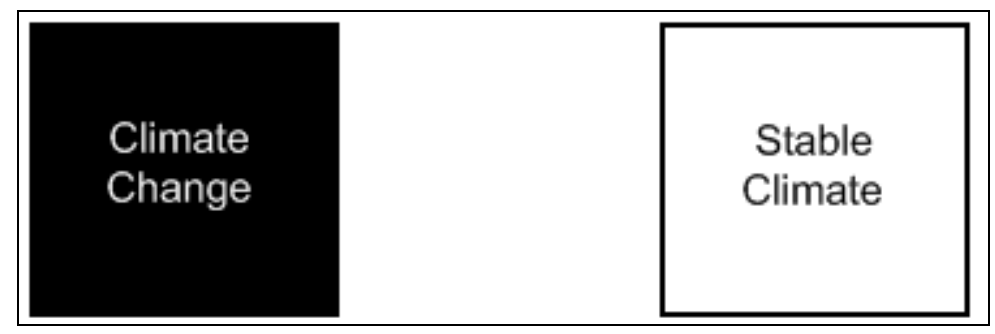

Figure 5 Dichotomous Climate Change appropriate to criticality

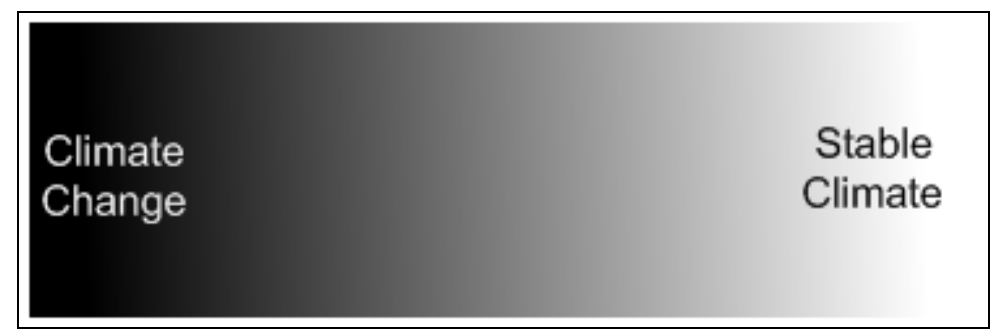

Figure 6 Continuous climate change appropriate to personal efficacy

The assessment of individuals as to whether they may have some influence upon an outcome of group behaviour is known as personal efficacy. It means that individuals believe they can produce a desired effect through their actions. When used in the context of the topic of this research the desired effect is a lessening of, though not necessarily complete halt to climate change as a result of modifications individuals make to their behaviour. It has been shown that when individuals believe they have a high level of personal efficacy, environmentally beneficial behaviour is more likely to result (Eden, 1993). Further evidence comes from the study of behaviour in public good situations. The greater the impact individuals believe they will have on the outcome the more likely they are to contribute (Laury et al., 1999).

Both the size of the problem and the group involved has a large influence upon personal efficacy. For one as the size the problem increases then the marginal benefit from each individual's contribution decreases. Decreases in the marginal benefit of an individual's contribution have been shown to lead to lowered levels of efficacy (Yu et al., 2009). Personal efficacy also decreases as group size increases (Kerr \& Kaufman-Gilliland, 1997; Seijts \& Latham, 2000). This is due in part to the decline marginal benefit from each individual that 
occurs as the number of individuals rises. But additional to this individuals believe that with a larger group co-operation declines and defections are likely to overtake contributions, wearing away any benefit from those contributions and thus reducing personal efficacy (Kerr, 1996). In effect, the huge, indeed global problem and group size of climate change could reduce personal efficacy to next to nothing. Comments such as' "I think that there are a lot of people who feel that no matter what I do I can't do anything about that [climate change] anyway"(Norgaard, 2006), are indicative that this evaluation of the situation does occur amongst individuals.

Although it is argued that personal efficacy is more appropriate for the problem of climate change than criticality from a strict evaluation of the problem, ultimately it is the judgement of individuals in the wider public that matters. Some evaluate the situation in terms of criticality and some in terms of personal efficacy. Therefore understanding both is important to changing behaviour.

\subsection{The Commons Dilemma as Motivation to Not Contribute}

A commons dilemma (also termed tragedy of the commons or in psychology literature a social dilemma) is a situation in which all individuals are better off if all co-operate, yet all have incentives to defect (Dawes \& Messick, 2000; Weber et al., 2004). Such a situation occurs with the provision of a public good. A public good is defined as one that is non-rival i.e. its use does not deplete it, and is also non-excludable i.e. when the good is provided, all individuals share in the benefit, even those that do not pay for or provide it. It is the non-excludable characteristic that is most important in creating the dilemma.

An informed self-interested individual, so theory suggests, wishes to see the public good provided because they benefit in some manner from the provision. But any self-interested individual also prefers not to pay for the good's provision if it will still be provided without their payment. For instance if the provision of a particular public good relies on 1000 equal contributing individuals then each person is responsible for $0.1 \%$ of the good. Following a self interested path of action any individual will be better off if they do not contribute and rely on everyone else to. By acting in this manner they receive a good that in $99.9 \%$ of what it might have been, at no cost to themselves. This behaviour is known as free riding. Eventually, each individual following this rationale, all will defect from contributing to the good and none will receive any benefit. In reality defections do not reach $100 \%$ because self-interested, egoistic decision making is not the only factor important to deciding whether people contribute or not 
(Biel \& Gärling, 1995; Cremer \& Dijk, 2003; Weber et al., 2004). But when personal interests are affected by either the outcome of or solution to a commons dilemma, self interest tends to play an important role compared with other motivations, for instance justice or fairness (Müller et al., 2008).

Other characteristics influential in deciding whether an individual contributes or not in a commons dilemma are the size of the group involved, the temporal element and if anonymity of contributions exists. Defections from the group become more frequent when contributions required are multiple or ongoing and take place over a long period of time (Clark \& Sefton, 2001; Isaac et al., 1985). Increasing the group size involved in the commons dilemma also leads to a higher rate of defection (Isaac \& Walker, 1988). When contributions to a public good are anonymous the result is lowered levels of cooperation (Bixenstine et al., 1966; Fox \& Guyer, 1978).

Free-riding is among the most important factors behind decisions to not contribute in a commons dilemma. It may influence either directly, as is the case when individuals decide to free-ride on the contributions of others, or indirectly. Indirectly refers to instances in which a belief that others will free-ride leads to the decision to not contribute. Individuals' considerations and experiences of the free-riding motive and its effect on the actions of others are known to influence their decisions concerning how to act to solve the dilemma (Gachter \& Thoni, 2004; Wade-Benzoni et al., 1996). When this motive is recognised or perceived it can lead to the decision to not contribute to a public good. Evidence to support this has been found by Hindriks and Pancs (2002) who have shown that individuals are more likely to donate to the provision of a public good when the probability of others doing so is high. Similarly both Biel and Garling (1995) and Green-Demers et al. (1997) have found that a belief others will act in the same manner as oneself leads to lowered uncertainty and subsequently a higher rate of cooperation.

Among the reasons for lowered cooperation when free-riding is believed to exist are powerlessness (Vasi \& Macy, 2003) and fairness (Clark \& Sefton, 2001). Powerlessness, as influenced by free-riding, takes the form of a belief that the individual's contribution is insignificant by itself and that others will continue to not join any necessary cooperative effort thus making the desired result impossible to achieve. This is evident in the way in which climate change, as an example of a commons dilemma, can elicit such responses, used to justify inaction, as 'I alone can do nothing, I can achieve something only if the others join',(Stoll-Kleemann et al., 
2001). For the individual this is powerlessness over the outcome. Fairness is addressed in detail in the following section.

What matters is not so much whether free riding occurs, but whether or not the motivation to free ride is perceived by those making decisions either to contribute or not. In most instances the behaviour of others in a commons dilemma remains unknown and it is the uncertainty about what choices others will make that is important for determining an individual's behaviour (Biel \& Gärling, 1995; Green-Demers et al., 1997; Hindriks \& Pancs, 2002).

\subsubsection{Fairness and Equity}

In addition to effects upon powerlessness free-riding also contributes to inaction on climate change by way of concerns about fairness and equity. Fairness, in a public goods situation, can be defined as 'the desire to be kind to those who signal kindness through their actions and to hurt those who signal hostility through their actions' (Keser \& Winden, 2000). Considerations of fairness are known to have an effect on the behaviour of individuals in commons dilemmas. Fehr and Schmidt (1999) have shown that sometimes even fair-minded individuals are likely to not cooperate in the provision of a public good when they consider there to be just a small number of unfair or self-interested individuals present who will not cooperate and punishing those individuals is impossible.

It seems unlikely that mitigation of climate change could be a public good which will allow for the punishment of non-cooperators and so it is expected that considerations of fairness and equity along with powerlessness will be causes of inaction that arise from perception of or concerns about free-riding by others, in terms of mitigation effort.

Although not linked directly with powerlessness fairness and equity concerns are addressed here because of the similar causes and in the interests of presenting a complete picture.

\subsubsection{Climate Change as a Commons Dilemma}

Climate change is a clear example of a commons dilemma (Milinski et al., 2006; Pfeiffer $\&$ Nowak, 2006). The benefits of the mitigation of climate change are non-excludable and nonrival and it therefore fits the criteria of a public good. The added mitigation of climate change resulting from an individual changing behaviour, e.g. changing mode of travel, represents only a very small marginal increase. The added costs of changing that behaviour represent a large 
marginal increase for the individual such that the individual responsible for the action will, if egoistic, wish to continue their current course of action and let others bear the cost of changing behaviour to mitigate climate change i.e. they will wish to free-ride. It is therefore understandable that the individual continues to undertake activities which contribute to climate change. The problem also fits all the criteria covered in the preceding two sections which should lead to the commons dilemma being an important cause of inaction on climate change due to free-riding. Climate change is a commons dilemma with a long time frame, a global group size and actions that contribute to or mitigate climate change are, for the most part, anonymous (Milinski et al., 2006; Pfeiffer \& Nowak, 2006). The result of this is that even individuals who are not egoistic recognise that climate change is a problem likely to be affected by free-riding. They then incorporate this knowledge into their decision making process and as a consequence of this they decide to contribute a reduced amount.

\subsection{Coping with Conflicts of Norms and Values}

Many of the above ways in which powerlessness is caused require some degree of comprehension and thought about the issue of climate change. For instance a judgement of being too insignificant to affect change requires a consideration of the global scale of climate change and the individual's place within the associated group.

But powerlessness also acts as a barrier to behaviour change in ways that require little comprehension and thought. This occurs when making a decision on a course of action is complicated by conflicting norms and/or values associated with two or more mutually exclusive choices. In such a case an individual can delay or avoid the decision by the use of powerlessness as a justification for inaction.

Individuals generally have norms to act in a socially responsible manner (Schwartz \& Howard, 1981). Pro-environmental actions are one form of socially responsible behaviour. However such behaviour has costs which conflict with personal, egoistic, values, for instance paying for carbon offsets costs money which might be spent on other goods or services. When such costs and difficulties in carrying out a behaviour are encountered norms are found to have little predictive power regarding actual behaviour (Corraliza \& Berenguer, 2000). To understand this it is useful to draw on Schwartz and Howard's (1981) normative decision making model of behaviour. This model predicts that if individuals must choose between conflicting norms to follow when making a decision they react by denying any ability to make a difference i.e. 
labelling themselves powerless. This has the effect of allowing the individual to avoid making a difficult decision between the conflicting norms.

In section 4.2.3 it has been shown that this model of decision avoidance and justification via powerlessness applies to conflicts regarding information. That the conclusion of this model should also apply to conflicts between norms and values is a reasonable assumption. Especially in light of research showing that people are likely to justify inaction through powerlessness when they feel the costs of change, a danger to egoistic values, are high (Kerr \& Kaufman-Gilliland, 1997).

Lorenzoni et al. (2007) suggest that also influencing decisions in which a conflict between pro-social norms and personal values are present is guilt. Individuals act to justify and overcome guilt at not taking action i.e. not following pro-social norms; by suggesting they 'couldn't have made a difference anyway'. This result is exactly what is expected if Schwartz and Howard's (1981) normative decision making model also applies to conflicts between norms and values.

\subsection{Summary: Powerlessness and the Commons Dilemma}

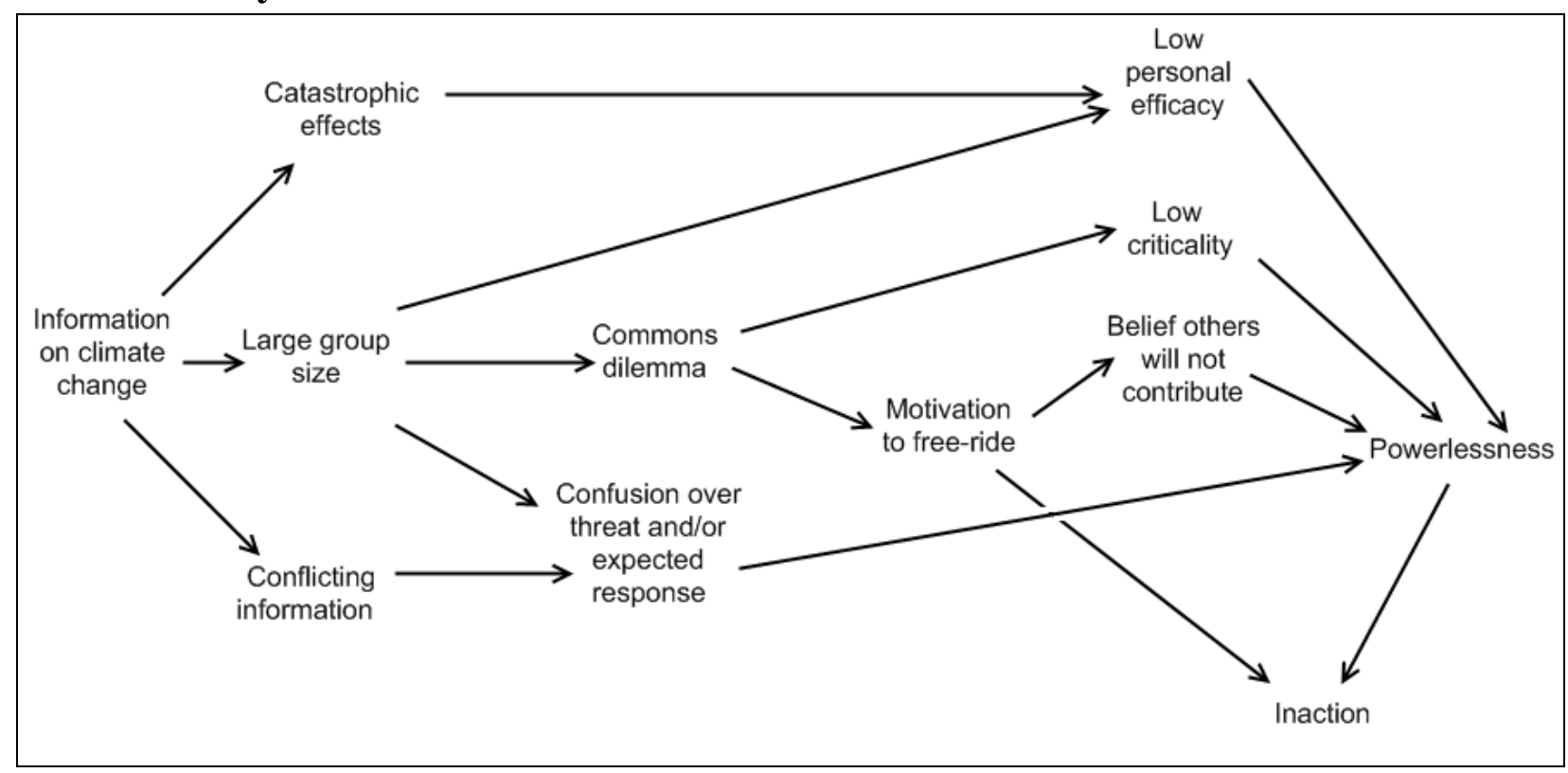

Figure 7 Diagram of influences and effects of powerlessness

Figure 7 presents a model of powerlessness that may be drawn from the current understanding of the perception with the literature. Powerlessness on the issue of climate change is linked to three key matters. Firstly there is the scale of the issue, secondly the individual's assessment of the behaviour of others, thirdly confusion on the subject is also of importance. 
The issue of scale contributes to powerlessness as individuals feel insignificant with respect to their ability to improve the situation, i.e. they have low levels of personal efficacy. In the case of climate change the global scale makes any one individual's contribution seem so small that it can have no effect. The chief influence on this perception of powerlessness due to insignificance is information that attributes expected or current catastrophic occurrences to climate change.

Concerning the role of others, it is the perceived incentive to free-ride, resulting from the commons dilemma nature of climate change that contributes to inaction via powerlessness. This incentive leads to a belief that others will not join in working towards a solution, preventing the achievement of a positive outcome. Individuals also take into consideration their own position and importance compared to others and the group as a whole. The huge group size involved in climate change means that each individual is only a negligible part. This should reduce personal efficacy and criticality to close to zero. The result of this is powerlessness.

Confusion has a significant impact on powerlessness. Confusion occurs on two subjects, the first is the science of climate change and the second is the expected response of the individual. When unable to reach firm conclusions on either of these subjects individuals are unlikely to take action and will justify this by declaring themselves to be powerless to affect change.

Based on these findings it is expected that powerlessness is prevalent as a cause of inaction towards mitigating climate change. Powerlessness with its varied causes generally means one thing for individuals: they consider that regardless of how they act the outcome will be the same. This is expected to be of importance in influencing behaviour towards climate change. 


\section{The Present Study}

\subsection{Gaps in Knowledge and Direction of Research}

Current understanding of powerlessness is not adequate for the purpose of designing effective campaigns to minimise and/or overcome the barrier to action it presents. The available theory and research suggests that powerlessness is an important influence on people's actions regarding environmental issues such as climate change, but there exists little available evidence to confirm or reject this either internationally or in New Zealand. There is an adequate understanding of powerlessness in relation the commons dilemmas cause, for example the effects of criticality and personal efficacy in addition to the ways in which information contributes to powerlessness; however the relative importance of these factors, both in relation to each other and other possible causes of inaction, is not well understood.

Nor is the importance of powerlessness in relation to the specific issue of climate change often addressed in the literature. These are significant gaps in current knowledge about perceptions of powerlessness and climate change. This has implications for the effectiveness of campaigns to change behaviour voluntarily. The aim of this research is to determine the importance of powerlessness in relation to other causes of inaction on climate change. Once that is clarified the relative importance of the various causes of powerlessness will also be studied.

\subsection{Hypotheses}

The broader aim of this research is to build up a picture of how individuals perceive climate change and how those perceptions affect their behaviour. In particular individuals' perceptions of powerlessness and the commons dilemma are examined in more detail. Five hypotheses will be tested to achieve this. They are as follows:

\section{A high perception of powerlessness is associated with a lowered level of action on climate} change.

Heightened levels of powerlessness have been shown to lead to lowered levels of action on general environmental issues by other researchers (Haller \& Hadler, 2008). Climate change is not expected to differ in the way individuals respond to powerlessness. 


\section{A high perception of the commons dilemma is associated with a lowered level of action on climate change.}

In cooperative situations in which a commons dilemma exists individuals are less likely to contribute to any necessary action (Dawes \& Messick, 2000). Climate change is an example of a commons dilemma (Milinski et al., 2006) and therefore it is expected that individuals who rate the commons dilemma highly will take less action.

\section{A high level of information is associated with a high level of powerlessness.}

Within the literature different studies of the effects of information on powerlessness have given conflicting results. Bord et al. (2000) and Haller and Hadler (2008) have found that individuals with greater levels of information, on climate change and environmental problems respectively, have lower levels of powerlessness. Other research by Kellstedt et al. (2008) indicates the opposite effect. This hypothesis is therefore included in order to clarify this debate.

\section{A high level of information is associated with a low rating of the risk of climate change.}

This hypothesis is closely related to hypothesis 3. Kellstedt et al. (2008) have found that individuals with greater knowledge about climate change show less concern about the risks of climate change. Both Bord et al. (2000) and Haller and Hadler (2008) have shown that individuals with less concern about environmental issues are less likely to take action. Since many campaigns aiming to increase pro-environmental behaviour rely on giving information about a problem to individuals the results of Kellstedt et al. (2008) are of great importance for future campaigns. The aim of this hypothesis is to test this finding.

\section{A high rating of the risk of climate change is associated with a high perception of powerlessness.}

Research suggests that individuals who believe the risks associated with climate change are high are also more likely to be powerless about the possibility of mitigating climate change (Niemeyer et al., 2005). If true this finding has severe implications for the Knowledge-Deficit Model which involves informing target individuals about the risks associated with certain behaviours. Testing this hypothesis adds more data to this currently underexplored topic. 


\section{Methodology}

\subsection{Overview}

Research on the questions in the previous section was conducted through three key methods, searches of peer-reviewed journal articles, focus groups and a survey. Journal articles provided the information necessary for the shaping and direction of research. Qualitative data was collected via four focus groups. A survey of members of the public was then conducted to provide vital quantitative data on the importance of powerlessness. The combination of focus groups and a survey represents a mixed-method approach and has been chosen because both methods combined are able to provide a more complete picture than either alone (Creswell \& Clark, 2007). Journal articles were then used once again to provide the framework needed to analyse and interpret the results of the primary data collection.

\subsection{Literature Review}

A literature review has provided the basis for this research. As is expected of such a process the literature review both set the context of this research and shaped its direction (Garson, 2002). Searches were limited to peer reviewed journals in order to achieve the highest level of conclusiveness possible from the review. An exception was made in a small number of instances when peer reviewed journals were unable to provide desired information on the topic. The literature review was conducted using both general and academic search engines that cover many peer reviewed journals.

\subsection{Focus Groups}

\subsubsection{Focus Group Organisation}

Whilst a survey provides valuable information on the importance of powerlessness and the various reasons for that perception it does not provide more detailed qualitative information on people's experiences of this perception. This information may be invaluable in exploring some of the reasons why people feel powerless. In order to uncover these reasons it is useful to facilitate focus groups where a more detailed discussion takes place. This is an accepted method of gathering qualitative data (Strauss \& Corbin, 1990) and a good means of using qualitative data to overcome the shortfalls of quantitative data (Creswell \& Clark, 2007). Through the discussions, undertaken for this research, individuals are asked to elaborate upon topics focussed 
around their actions or inactions towards climate change and their underlying motivations. The focus groups have two key purposes: one, to uncover possible reasons and causes of inaction on climate change overlooked or missed during the literature review process and two, to investigate why people perceive powerlessness. This kind of qualitative information is difficult to obtain via a survey only. A total of four focus groups were held to obtain this information. This attracted a total of twenty one individuals. All involved were over the age of 18 years. Due to the limitations of this study they were all held within the greater Wellington region. In recognition of the many differences present within the Wellington population four locations with differing socio-demographics were chosen for focus groups; Karori East, Karori Park, Berhampore (all within Wellington City) and Lower Hutt. Participants were sought via a pamphlet drop in the vicinity of each focus group. A \$20 supermarket voucher was given to each for their time.

Table 1 Socio-demographics of census areas where focus groups were held from 2006 Census (StatsNZ, 2006a)

\begin{tabular}{|r|r|r|r|r|}
\hline & Karori East & Karori Park & Berhampore & Lower Hutt \\
\hline Population & 3,468 & 4,122 & 2,595 & 97,701 \\
\hline $\begin{array}{r}\text { Education (post } \\
\text { high school) }\end{array}$ & $65.9 \%$ & $56.3 \%$ & $46.7 \%$ & $40.5 \%$ \\
\hline $\begin{array}{r}\text { Income (median) } \\
\text { Families with } \\
\text { Children }\end{array}$ & $\$ 38,200$ & $\$ 32,000$ & $\$ 24,000$ & $\$ 27,300$ \\
\hline 3 or more & $65.5 \%$ & $61.4 \%$ & $58.8 \%$ & $65.3 \%$ \\
vehicles & $9.9 \%$ & $8.3 \%$ & $4.7 \%$ & $12.0 \%$ \\
\hline
\end{tabular}

But there are still problems inherent in such quantitative research. Focus groups are subject to self selection, tending to attract individuals who are particularly interested in the issue or with strong opinions. It is therefore noted that it is not the aim of focus group research to be representative of the wider community's views. Additionally focus groups provide data that is much more subject to the interpretation of the researcher and bias may result from this also (Creswell \& Clark, 2007). 


\subsubsection{Focus Group Topics}

The central purpose of the focus groups was to explore powerlessness on the issue of climate change within a general theme of inaction on the matter. The three main themes covered were; knowledge about the issue; personal actions; and perceptions, first about the size of the issue and secondly about the role of others.

\section{Knowledge}

Discussion initially focussed upon participants' general knowledge of the climate change issue. The Values-Beliefs-Norms framework of behaviour (Stern, 2000) predicts that beliefs about individuals' ability to reduce a threat are important determinants of behaviour and knowledge is important in the formation of these beliefs. Knowledge was therefore explored to build context for later discussion of specific beliefs about powerlessness. Empirical findings by Haller and Hadler (2008) support the hypothesis that higher general knowledge about the environment relates to lower levels of powerlessness. Theory (Jackson, 2005) and research relating specifically to climate change (Kellstedt et al., 2008) back these findings up. The questions discussed were:

- What do you think causes climate change?

- Who is responsible for climate change?

- Can climate change be stopped?

- What needs to happen to stop climate change?

\section{Personal Actions}

Discussion then looked more closely at the beliefs of individuals regarding perceived ability or inability to make a difference to the outcome of climate change. This was examined by looking at both society as a whole and the role of individuals. The questions discussed were:

- Do you take any actions to lessen climate change?

- What effect do you believe these actions achieve?

- Do you think you could take more actions?

- Why do you not take some actions?

\section{Perceptions of the size of the problem and other's roles/actions}


In order to uncover the reasons behind powerlessness, final discussion explicitly covered points expected to be important following literature review. These are: the role of the individual in the group i.e. personal efficacy (Eden, 1993; Kerr, 1996); information about large scale effects (Jackson, 2005; Kellstedt et al., 2008); and the commons dilemma nature of climate change (Isaac \& Walker, 1988; Stoll-Kleemann et al., 2001; Wade-Benzoni et al., 1996). The questions discussed were:

- If you think about the global scale of climate change what do you feel?

- How do you feel when you think about the problems like sea level rise?

- Would you voluntarily change your actions or make some payment to reduce climate change if you knew it would definitely have an impact?

- If you knew that by contributing you would cause somebody else to take no action would you still continue to do so?

\subsection{Survey Method}

Journal articles on the occurrence of fatalism in individuals in a variety of settings generally include measurements of powerlessness taken via survey or interview. Typically interview subjects are asked to evaluate a number of statements using a Likert scale in which they provide a rating in the form of a number (or phrase). This indicates their thoughts on the importance for them of various possible causes of a given circumstance or occurrence. For instance a survey of powerlessness in the United States of America (Cohen \& Nisbett, 1998) asked individuals to attribute various aspects of life, such as economic status, to causes ranging from God's will (high powerlessness) to hard work (low powerlessness). A study of political powerlessness in former Soviet countries (Goodwin \& Allen, 2000) asked respondents to evaluate questions such as 'Life is like a lottery' on a scale from 1 (very strongly disagree) to 5 (very strongly agree).

These research articles reported few problems with the method and Likert scales are generally accepted as one means of measuring powerlessness within psychology. The survey for this research therefore used a scale similar to Goodwin and Allen (2000). Respondents were asked to provide a rating between 1 and 5. For the main body of the questionnaire 1 represented 'Not Influential' and 5 represented 'Very Influential' (see Figure 8). Some questions used different measures where appropriate. A numerical scale was used, as the survey aims to uncover 
the relative importance of powerlessness and causes of powerlessness and a numerical system allows for easy comparison and analysis of scores on different variables.

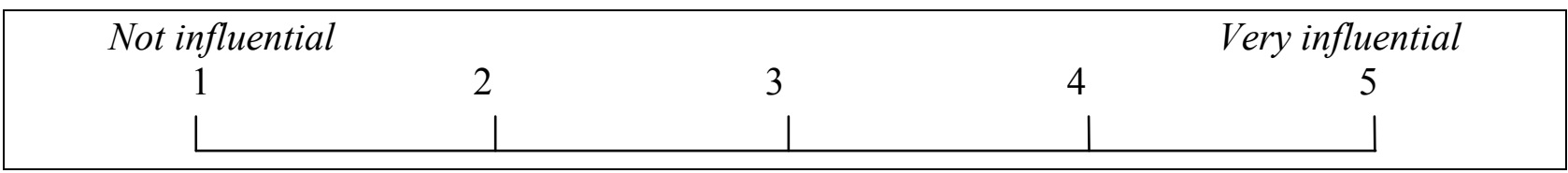

Figure 8 The Likert scale used for the main body (Questions 7 - 20) of the questionnaire

The questions covered a range of possible causes of inaction from cost to lack of knowledge. These were based on the focus groups undertaken for this research, the responses of interviewees from two studies of public perceptions about climate change in England (Lorenzoni et al., 2007) and Switzerland (Stoll-Kleemann et al., 2001) as well as questions derived to measure the importance of other factors found to be significant during the literature review.

A survey is quantitative data research. It is therefore recognised to have limitations that are inherent to this form of research. Of particular concern to the research is the fact that surveys hide the context in which people speak and also cover up individual voices that might otherwise provide valuable information (Creswell \& Clark, 2007). This reason and the problems associated with qualitative data collection already covered are why a mixed-method approach was chosen.

\subsubsection{Survey Questions}

Unless otherwise indicated, respondents were asked to answer question by giving a rating on a 5-point scale. See questionnaire in Appendix 2 for specific scales used for each question. The questions were as follows:

\section{How well informed do you consider yourself on the issue of climate change?}

The purpose of this question was to enable the study to examine the possible relationship between knowledge on the issue of climate change with both levels of concern and powerlessness. Consistent with Kellstedt et al. (2008) an inverse relationship between knowledge of climate change and level of concern was expected. A decrease in an individual's level of concern about climate change when knowledge of the issue increases seems counter-intuitive and raises further questions about the accuracy of the measure i.e. the individual may mistakenly believe they 
possess all the information needed to make a judgement. However Kellstedt et al. (2008) show that self-reported knowledge on other environmental issues, e.g. pollution, correlates positively with increased levels of concern about the issue. They therefore suggest that individuals informed on climate change can reasonably be pessimistic about their ability to change the outcome and declare themselves unconcerned about the issue as a means of justifying inaction.

It is recognised that this is a self-reported measure and as such is open to different interpretation. For instance within the U.K. many individuals who reported themselves as highly or moderately informed on climate change believed, erroneously, that the ozone hole and climate change were tightly linked problems (Lorenzoni et al., 2007).

\section{To what extent do you believe human activity is contributing to climate change?}

The very idea of changing behaviour to lessen climate change requires that the phenomenon be caused, at least in part, by human activities. If individuals consider climate change to be entirely natural then the rest of their responses are likely to reflect this and they are logically less likely to have seriously considered any behaviour change.

\section{How severe do you consider the problem of climate change?}

Kellstedt et al. (2008) suggest that higher levels of knowledge about climate change and environmental problems respectively are associated with lower ratings of risk. Kellstedt et al. (2008) also find higher knowledge about climate change associated with higher levels of powerlessness. If these associations were also found amongst the sample group of this research then a negative correlation with knowledge (measured in Question 1), and a positive correlation with powerlessness due to lowered personal efficacy (measured in Question 15 below) were expected. Combination of this Question with Question 4 allowed for the creation of a Perceived Risk composite variable.

\section{How soon should climate change be dealt with?}

Questions 2, 3 and 4 provided the main information on respondents' beliefs about climate change as a problem. This question on the urgency which climate change needs to be dealt with provided a different perspective on how important the problem of climate change is considered 
by individuals. Urgency and severity are logically distinct but may in practice be conflated; hence a positive correlation with responses to Question 3 is expected.

\section{Have you changed your actions, at least partly, due to consideration of climate change?}

This key question enabled study of correlations between inaction and the possible causes that were investigated in later questions. It should be noted that as with measures of knowledge this is a self reported scale and therefore issues of accuracy are raised. It has been noted that self reported behaviours correlate better with intentions than actual behaviours (Stern, 1992).

\section{How much has climate change been a factor in changing your actions?}

There are often co-benefits from behaviour that is beneficial in lessening climate change e.g. monetary savings to the individual. This question enables evaluation of whether these other benefits were more influential than any desire to lessen climate change. Despite the potential limitations with this question, which are the same as those noted for question 5, the question was vital to determining the degree to which individuals are acting in relation to climate change. Trials of the questionnaire found that asking Question 5 alone caused confusion and more importantly masked differences between climate change being the primary reason for change or merely a small factor.

Questions 7 to 20 are all possible reasons for inaction on climate change. They are presented under the general heading of:

\section{How influential have the following factors been in shaping your own decisions about actions that might affect climate change?}

The aim of this section was to uncover which factors, both psychological and otherwise, were seen as having the greatest relative importance in causing inaction. All the possible reasons for inaction included in the questionnaire were based upon the focus groups conducted prior to the survey, research by others such as Stoll-Kleemann et al. (2001) and Lorenzoni et al. (2007), and reasons predicted to be of importance based upon literature review, e.g. personal efficacy (Kellstedt et al., 2008; Kerr \& Kaufman-Gilliland, 1997) and information (Barr \& Gilg, 2007; Jackson, 2005). 


\section{The monetary cost of changing my actions}

This question measured the importance of financial factors in causing inaction, for instance the cost of choosing a hybrid vehicle rather than a less fuel efficient alternative can prevent change. By combining Questions 7, 8, 9 and 10 the composite variable Option Difficulty was created.

\section{The availability of options for change}

If options for change are not available, then psychological factors will be of little importance for predicting inaction. For instance an individual may feel they can make a difference to climate change by driving less but is unable to switch due to the unavailability of public transport suiting their needs.

\section{The inconvenience of options for change}

Financial costs to change are not the only costs. This question measured the importance of inconvenience that is associated with changing habits, e.g. having to wake earlier to catch a bus.

\section{Fitting changes in with family and others}

Inconvenience is one of the costs associated with changing behaviour. This was partially examined by Question 9. This question examines whether inconvenience about change is caused not directly by the change or alternatives, but indirectly due to necessities of fitting schedules with and meeting the needs of others.

\section{Lack of knowledge about possible changes I can make}

Communications to change behaviour based on the knowledge deficit model have often included information on possible changes people can make to alter their impact upon the environment (Barr \& Gilg, 2007; Barr et al., 2001). This question measured this by asking whether ignorance about choices is influential in predicting inaction by individuals. By combining with Question 12 an Option Uncertainty composite variable was able to be formed. In addition to this a general Confusion composite variable was able to be formed by combining Questions 11, 12 and 13. 


\section{Uncertainty about the best options to contribute to reducing climate change}

Evidence from Anderson (2003) suggests that individuals will put off decisions and/or actions until they are certain about the reasoning behind the decision and the consequences resulting from it. This question measured the importance of so called 'inaction inertia' in relation to climate change decisions.

\section{Uncertainty as to whether climate change is a significant problem}

While Question 11 and 12 focus on information about 'solutions', Question 13 focuses on uncertainty about the problem. Evidence suggests that individuals may respond to complex and contradictory messages about climate change by categorising the topic as uncertain and not acting on the issue until that uncertainty is resolved (Kaplan, 2000; Schwartz \& Howard, 1981). This question allowed investigation of this prediction.

\section{The feeling that climate change is too big for my actions to have an impact}

This question directly measured powerlessness. A widespread perception of powerlessness is expected given the messages and information in the media and elsewhere that portray climate change as either a huge or global problem (Barr \& Gilg, 2007; Jackson, 2005). This question will evaluate the importance of this particular cause by looking at how individuals' perception of the scale of the issue affects their judgements on the potential to make a difference. Together with Question 15 and 16 a Powerlessness composite variable was able to be formed.

\section{The feeling that my actions will not affect the outcome of climate change}

This question addressed powerlessness in the form of beliefs about scale and criticality. When making decisions about contributing to a public good individuals tend to consider whether they believe their contribution will make the difference between provision or not (Cremer \& Dijk, 2002). Individuals may or may not assess actions beneficial to climate change outcomes in such a manner. However the question was included in order to examine this.

\section{The feeling that my contribution is just a drop in the ocean and so is insignificant}

This question also addressed powerlessness and scale in the form of beliefs about personal efficacy. This matter is central to powerlessness. Individuals, when deciding whether to take 
collective action, consider their place within the group (Olson, 1971). When group size is large individuals are expected to feel a low ability to make any difference to an outcome (Kerr, 1996) and a low willingness to contribute to protecting the environment (Eden, 1993). Collective action is applicable to climate change solutions and the large group size is expected to reduce the belief of individuals that their contribution matters to very low levels. It is therefore predicted that answers to this question will show it to be influential and correlated with low levels of acting upon climate change. Whether this shows a positive correlation with knowledge on the issue is also of interest. If it does it provides backing for the idea that more information on climate change could promotes powerlessness.

\section{Feeling that other individuals will not change their actions even if I do}

This question addressed association between powerlessness and the commons dilemma. In commons dilemma situations individuals consider the actions of others when determining their own behaviour and when free-riding is expected contributions are decreased (Wade-Benzoni et al., 1996). With a large group, as climate change entails, free-riding in expected to be more prevalent (Isaac et al., 1985). It is therefore expected that this is influential and shows a correlation with inaction. As with Question 16 a correlation with knowledge on the issue will be of interest. Together with Question 18 and 19 a Commons Dilemma composite variable was able to be formed.

\section{Unfairness associated with bearing the cost of change whilst others do not}

Research has shown that fairness considerations play a part in deciding an individual's actions in a commons dilemma (Fehr \& Schmidt, 1999). This question therefore examined this to see if fairness is important in deciding individuals' action on climate change.

\section{Other countries or people not taking equivalent action currently}

This question measured the degree of importance individuals attach to the equivalence of actions by others. This factor should be important according to previous research (Wade-Benzoni et al., 1996). The decision to classify others as both people and countries was made on the basis of information acquired during focus group research. Discussion on this topic frequently led to 
participants citing both other individuals and other countries as examples of those not taking action currently. It also opens up an international comparative perspective.

\section{Looking foolish due to being the only one to change actions}

This question measured whether individuals feel pressure to act in the same way as their peers. If it is shown to be a strong influence it could suggest that social norms exist which favour acting in a non-environmentally friendly manner until others do so.

The remaining questions were socio-demographic:

\section{Please indicate your age and sex}

Under 20

$20-29$

$30-44$

$45-59$

$60+$

Male/Female

This question allowed for the data to be analysed for possible correlations between powerlessness, age and sex. Five categories are provided to allow for reasonable resolution of data.

\section{What is your highest level of education?}

No Qualification

High School Qualification

Tertiary Degree

Tertiary Other 


\section{If you don't mind, please indicate your individual income?}

$\$ 0-\$ 25,000$

$\$ 25,001-\$ 50,000$

$\$ 50,001-\$ 75,000$

$\$ 75,001+$

These questions allowed for data to be analysed for possible correlations between powerlessness, education and income.

\subsubsection{Administering}

The survey was conducted by requesting responses from a sample of individual passersby on the street conducted between $12 \mathrm{pm}$ and $2 \mathrm{pm}$ on three days, the $11^{\text {th }}, 12^{\text {th }}$ and $14^{\text {th }}$ of November 2008. Individuals approached were offered the chance to complete the questionnaire and in return were offered a chocolate bar as a token reward. Three locations in Wellington and Lower Hutt cities were chosen. This was to achieve a broader sample of people than one site is likely to provide. It is recognised that this method is imperfect and may over represent Wellington and Lower Hutt office workers. However given the time and money constraints present, the required locations were needed to be both within Wellington and with high volumes of foot traffic making these three locations the best option.

\subsubsection{Locations}

Location 1 - Midland Park, Corner of Lambton Quay and Johnston St, Wellington Location 2 - Corner of Cuba Mall and Dixon St, Wellington Location 3 - Corner of Bunny St and Queensgate St, Lower Hutt

Due to the nature of the locations which have high daytime populations but relatively low immediately resident populations a summary of socio-demographic statistics for the immediate area surrounding the survey location would provide an inaccurate picture of the survey respondents. Therefore socio-demographic statistics are given here for the local suburban region. 
Basic socio-demographic statistics of the respondents at each location are given in the results section.

Table 2 Socio-demographics of survey areas from 2006 Census (StatsNZ, 2006a)

\begin{tabular}{|r|r|r|r|}
\hline & Wellington City & Lower Hutt & New Zealand \\
\hline Population & 179,463 & 97,701 & $4,143,279$ \\
\hline Education (post high school) & $55.5 \%$ & $40.5 \%$ & $40.0 \%$ \\
\hline Income (median) & $\$ 32,500$ & $\$ 27,300$ & $\$ 24,400$ \\
\hline Couples with Children & $43.2 \%$ & $44.7 \%$ & $42.0 \%$ \\
\hline Age (median) & 33.1 & 35.1 & 35.9 \\
\hline
\end{tabular}




\section{Results}

\subsection{Focus Group Results}

This section presents the findings from the four focus groups conducted. Confidentiality of the participants was important and therefore names have been omitted. All quotes are taken from discussions. Text in square brackets is used to improve the clarity of quotes where relevant. In order to allow ease of reading 'ums' have been removed. Results presentation is structured around the three key themes of the discussions addressed in chapter 6.3.2

\subsubsection{General Knowledge and Beliefs about Climate Change}

When asked what the causes of climate change were participants provided a wide range of different answers on both specific and nonspecific causes. The most common answer given was a nonspecific cause, that of pollution or industrial waste.

\section{Industrial fumes and waste and things like that.}

Brought about by the industrial revolution.

Different types of pollution. Related to radiation and nuclear experiments. Anything that is bad for the Earth. Free radicals and car fumes.

Because of airplanes. There's a lot of pollution, and the cars and industry, smoke.

Put it down basically to industry. Even if it was natural it wouldn't be happening this quickly. To do with chemistry and chemicals and everything we're pumping into the environment generally I would say.

There was general agreement from members of the focus group who did not add additional information when these answers were given. Some gave more detailed answers providing a specific cause. Of those carbon emissions or $\mathrm{CO}_{2}$ was the most frequently cited direct cause.

Carbon emissions. Carbon dioxide, the amount that is pumped into the atmosphere.

Carbon emissions

The ozone hole was also frequently named as a specific cause of climate change. 
I think partly it could be depletion of the ozone layer. That area around Antarctica has increased quite markedly. I remember in the 1970's the concern about the propellants that are used for sprays and things, chlorofluorocarbons I think they're called, they were quite widespread. People were using them in sprays and things. That could be a major cause of pollution in the atmosphere.

Natural thinning of the ozone layer in parts of the world such as the Antarctic.

Only one participant expressed knowledge of deforestation as a cause of climate change. Three participants expressed knowledge of previous historical changes in climate. Only one participant showed a level of skepticism or denial about anthropogenic causes of climate change

There's some doubts about the connection between carbon dioxide and global warming. The planet is warming certainly.

Discussion then moved on to cover who was responsible for climate change. Participants generally laid the responsibility with large organizations or groups. Responsibility covered two different issues; one was which groups were causing climate change. The second was which groups needed to put efforts into fixing the problem. Three of the four discussions saw China raised as a particular country responsible for causing current and future climate change. In particular China was seen as responsible due to rapid growth and large industrial output.

Chinese.

Bigger countries that are pushing their production above the needs of the rest of the world, so I guess countries like China, pushing their production all over the place and not really thinking about the consequences.

For some participants blaming China was coupled with an expression of futility about solving the problem. 
Whatever we do in the western world is going to make no difference while China is going down the path they are now.

Governments were frequently named as responsible for taking action to address the problem of climate change.

The world leaders, those in power and authority. They control every individual country through legislation.

...it's up to governments to try and regulate things.

You could say governments in general. Maybe sort of have the power to influence. They can outlaw certain types of fuel burning. Or they can encourage it and therefore cause [climate change].

The role of individuals, including themselves, was also raised on numerous occasions.

I think we all are as individuals.

99.99\% of the population, except a few greenies.

The ultimate cause is the population being so large.

When asked if climate change could be stopped responses across all groups tended towards the belief that climate change might possibly be slowed but not stopped altogether.

I think the impact can be minimised or slowed, but it can't be stopped.

I think it can be slowed down but not really stopped. 
The natural forces are far too great, far too great.

One participant noted that a 'tipping point' might have been passed which results in climate change becoming unavoidable. When questioned whether this had been reached he was unsure, but thought possibly it had already been passed. Some participants expressed views that if some large changes were to occur in society it might be stopped.

I think we could stop it if we got rid of half the world's population.

If someone created an alternative mainstream source of transport other than petrol. If suddenly there was no more oil tomorrow, I'm sure someone would create a technology and it could be environmentally friendly.

Others showed a belief in education about environmental problems and solutions. This was often directed at the younger generation.

I think too education. We can start with the next generation. Maybe you can change the way they look at things.

Education is the important thing. Especially if they educate from younger generations up to older ones. From primary right up to college. If they're educated at a young age they know what's going on and they know how to go about reducing pollution levels when they get to an older more responsible age.

A respondent at one of the groups believed there was a need for more awareness about the environmental effects of decisions and a shift from short term thinking to long term holistic thought. At another of the discussions a participant expressed a similar belief in the need for change from a consumer oriented society to a less wasteful one in which we are happier with less material possessions. Another common suggestion was for the government to become more involved in a solution by means of regulation to prohibit and reward certain behaviours. 
Government needs to make greater penalties for those that pollute and things that are harmful for the environment.

It's back to the government regulations again. I think you really need to start enforcing it.

Only one participant mentioned the use of household level measures as a means of stopping or slowing climate change.

Just doing things like turning lights off, walking, biking, turning off appliances, little things on an everyday basis. It will have an impact on the amount of electricity we use.

\subsubsection{Personal Actions Regarding Climate Change}

Participants were asked what, if any, actions they take to reduce their contribution to climate change. In answer to this almost all participants across all discussion groups named recycling first and foremost.

Yes, well recycling is the obvious one.

Recycling...

Following on from these points participants talked of reducing the use of various goods and services that they believed had some sort of impact on climate change. Note that the last quote and the next one were from the same sentence.

.....and you're just aware of wastage of water and power, and whether you use the car or not etc.

...I compost and recycle everything I can

Make sure plugs are turned off at the wall, if you're not using them. It's not much. 
Walk and use public transport rather than having the car.

At the supermarket level we use less plastic bags.

Growing one's own vegetables was mentioned at three of the four groups. One participant said that they had sold their car and bought a motorbike which cut down on petrol use and saved a lot of money. To this another participant replied that they thought that act and many of the others mentioned earlier were undertaken simply because they saved money and not due to concerns about climate change.

Discussion covered the topic of whether more actions could be taken by individuals to reduce their contribution to climate change. Participants generally believed that they did as much or close to as much as they could do to reduce their impact on climate change. Reasons for not taking action were also raised at this point. They will be addressed separately.

I think we could all do more.

I think I could do a lot more.

It's hard, but for me I think I do as much as I can.

Discussion in one group covered what was felt to be the limiting factor of unavailability of options for change. When this group was then asked specifically for actions they might take that were available to them now, there was no response.

Participants generally felt that the reasons they did not take more actions to reduce their impact on climate change were factors outside of their control. Participants in one group believed there was a bit more they could do but felt the chief limiting factor was a lack of appropriate schemes and facilities put in place by the local government to deal with waste. The inability to recycle plastics beyond number 2 and lack of an organic waste collection were given as examples. Businesses were also blamed for a lack of commitment to reducing waste through 
means such as biodegradable supermarket bags, eco-packaging and reducing excessive advertising material.

Meat packaging can be made out of cornmeal. It's biodegradable but costs money.

Discussion in other groups tended towards more personal barriers to taking action. Time, inconvenience and money were mentioned by several participants across three of the groups.

I think it comes back to money.

Keen to take more actions like insulation but I'm not entitled to any of the [monetary] benefits you can get [from the government] so to me it's a complete waste of time. There's no incentive to do it.

It's cheaper to be on the grid than invest in solar cells.

It's a question of time and cost....... We could all do more if it wasn't so timely, costly.

Probably convenience. You're out and about and it's difficult to recycle, got to take them [rubbish] home or just throw them out.

Several respondents expressed a belief that society today acts a barrier by creating a lot of pressure to accumulate goods and replace things swiftly rather than repair them.

The economic system in which we live. It's like the survival of the fittest, you feel helpless. I have to have something, just in case I lose my job. There's all this [pressure] to accumulate and work and all that has an environmental impact.

A lack of knowledge about options to change was raised at only one discussion group. It was raised in two different manners. The first and most prominent was a discussion regarding the lack of distribution of information about recycling and waste disposal. They were concerned by a 
lack of awareness about 'E-Day' a local electronics recycling event and about the correct way of discarding of paint until it were too late in both cases. The second time a lack of knowledge was raised it regarded uncertainty.

Uncertainty what the right action is.

\subsubsection{Perceptions about Climate Change}

The third theme of the focus groups focused on the perceptions that individuals had about climate change, both in terms of scale and the role of others. When asked how the global scale of climate change made people feel, initial responses at several focus groups were:

Powerless, totally powerless

Pretty small (at two groups)

Some participants then expressed stronger views on the issue.

Blame someone else, blame China, blame the [United] States.

It makes you wish you could sit down with George Bush and say, what are you doing to the environment?

Totally just pissed off

Some participants gave examples of what they felt was the insignificance of their actions when compared to the size of much larger users of resources.

As individuals we were turning off everything at home [due to concerns of electricity shortages resulting from low hydro lake levels], then you go outside and there's streetlights on everywhere, lights blazing in the offices. 
I think the Canterbury region uses more water in a week than the entire rest of the country. So even if we all stop running our taps while we brush our teeth and whatever, these [major] irrigators are using up all the water

The focus group was used to examine how people felt when they were presented with information about some of the catastrophic effects of climate change such as strengthened hurricanes and sea level rise. Most groups quickly joked about not living near the sea before moving onto more serious discussion.

I'm worried that something really drastic is going to have to happen before governments do anything about it.

\section{Disheartened again.}

We all know the ice caps are melting but what can we do about them? They're so far away.

Feel pretty powerless, why isn't anything happening [to stop the effects]. It is a bit demoralising.

Too depressing, go and do something else.

Some participants stated they simply hadn't thought about the issues either at all or in any detail. When further questioned as to whether they thought about any of these issues in connection with everyday acts like putting out recycling the response was no, they hadn't. Following on from this, participants were asked if they would voluntarily pay or take actions to reduce climate change if they knew that would definitely be a positive result from doing so. There was an almost universal agreement from those that responded that yes they would do something if they could see the benefits of making a payment or taking an action. 
Yes I would if I knew it would definitely make a difference.

Some participants gave more detailed answers, suggesting conditions they would like to exist or know about before making some such payment or taking an action.

If the cost is local I would expect the benefit to be local.

Depends how much you would be investing and what the gain would be.

At one of the discussions participants believed that such a voluntary scheme would be good but ultimately unlikely to solve the issue.

[voluntary behaviour] will only get 10-15\% of people, you won't get the mainstream.

I think you've really got to have the carrot and the stick. For those doing the right thing there needs to be some kind of financial benefit but there also has to be punishment for those doing harm. But I think there has to be a way to avoid it to reduce complaints.

Discussion then covered the hypothetical scenario of whether participants would still continue to donate to a scheme to reduce climate change if they knew that by doing so someone else would decide not to and instead free-ride upon their contribution. Participants at one group all agreed that they would still contribute. Those that provided a reason believed it would make them feel good or that if they were willing to contribute so too would others, even if some did not. From other groups participants gave similar responses.

I'd say yes because I'm a leader not a follower.

Yes because it's actually helping.

I think you've still got to do it. 
There's always been this block of society that are just completely disengaged with the values of the rest. The best we can do is be united as a majority.

Some participants though gave different responses.

I'd put less in because it would annoy me.

I'd be less enthusiastic.

Sometimes maybe. Sometimes you might say better that someone does it. 


\subsection{Survey Results}

\subsubsection{General Statistics and Socio-demographics}

Questionnaires were filled out by 201 participants. Nine questionnaires were discarded where more than $20 \%$ of the questions were not completed. Of those questionnaires entered for analysis, 79 were from Location 1, 57 from Location 2 and 56 from Location 3. Sociodemographic information collected from Questions 21, 22 and 23 is shown in table 3

Table 3 Comparisons of socio-demographics from survey and census (StatsNZ, 2006b)

\begin{tabular}{|c|c|c|c|}
\hline & $\begin{array}{l}\text { Survey Socio- } \\
\text { demographic }\end{array}$ & Census Statistics & $\begin{array}{l}\text { Difference Survey } \\
\text { - Census }\end{array}$ \\
\hline Age & & & \\
\hline Under 20 & $8.9 \%$ & $28.7 \%$ & $-19.8 \%$ \\
\hline $20-29$ & $35.9 \%$ & $13.2 \%$ & $22.7 \%$ \\
\hline $30-39$ & $21.4 \%$ & $14.3 \%$ & $7.1 \%$ \\
\hline $40-49$ & $15.1 \%$ & $15.0 \%$ & $0.1 \%$ \\
\hline $50-59$ & $8.9 \%$ & $12.1 \%$ & $-3.2 \%$ \\
\hline $60+$ & $8.9 \%$ & $16.7 \%$ & $-7.8 \%$ \\
\hline Unspecified & $1.0 \%$ & - & N/A \\
\hline Gender & & & \\
\hline Male & $48.4 \%$ & $48.9 \%$ & $-0.5 \%$ \\
\hline Female & $45.3 \%$ & $51.1 \%$ & $-5.8 \%$ \\
\hline Unspecified & $6.2 \%$ & - & N/A \\
\hline Education & & & \\
\hline No Qualification & $6.2 \%$ & $25 \%$ & $-18.8 \%$ \\
\hline High School Qualification & $27.1 \%$ & $35 \%$ & $-7.9 \%$ \\
\hline Tertiary Degree & $43.8 \%$ & $11 \%$ & $32.8 \%$ \\
\hline Tertiary Other & $21.4 \%$ & $29 \%$ & $-7.6 \%$ \\
\hline Unspecified & $1.6 \%$ & - & N/A \\
\hline Income & & & \\
\hline$\$ 0-\$ 25,000$ & $21.4 \%$ & $45.8 \%$ & $-24.4 \%$ \\
\hline$\$ 25,001-\$ 50,000$ & $34.4 \%$ & $27.9 \%$ & $6.5 \%$ \\
\hline$\$ 50,001-\$ 75,000$ & $18.8 \%$ & $8.9 \%$ & $9.9 \%$ \\
\hline$\$ 75,001+$ & $20.3 \%$ & $7.3 \%$ & $13.0 \%$ \\
\hline Unspecified & $5.2 \%$ & $10.2 \%$ & $-5.0 \%$ \\
\hline
\end{tabular}

A comparison of the socio-demographic data collected in the survey and the census data for the entirety of New Zealand shows several notable differences. 
A considerably lower proportion of those who completed the survey were under 20 years of age compared with the whole population. A greater proportion of those completing the survey were aged between 20 and 39 than in the whole population and fewer are in the groups higher and lower (over 60 and under 20)

Male and Female proportions show no notable differences from the wider population data. The survey participants had much higher education levels than the general population. Most notable was the higher proportion holding tertiary degrees. Also noteworthy is the much lower proportion having no qualification when compared with the general population.

The survey socio-demographic had higher incomes than the nation as a whole. There was a lower proportion earning $\$ 25,000$ or less. The other income brackets all showed higher proportions in the survey participants, in particular the $\$ 75,001+$ group. 


\subsubsection{Results from Questions 1 - 6 Knowledge and Attitudes about Climate Change}

Table 4 presents the results of the first six questions from the survey. They provide the data on respondent's levels of knowledge, attitudes and actions regarding climate change.

Table 4 Results of Survey Questions 1 -6

\begin{tabular}{|l|l|l|}
\hline Question & Mean & Standard Deviation \\
\hline $\begin{array}{l}\text { 1. How well informed } \\
\text { do you consider } \\
\text { yourself on the issue } \\
\text { of climate change? }\end{array}$ & 3.17 & 0.89 \\
\hline $\begin{array}{l}\text { 2. To what extent do } \\
\text { you believe human } \\
\text { activity is contributing } \\
\text { to climate change? }\end{array}$ & 3.95 & 1.05 \\
\hline $\begin{array}{l}\text { 3. How severe do you } \\
\text { consider the problem } \\
\text { of climate change? }\end{array}$ & 3.83 & 0.96 \\
\hline $\begin{array}{l}\text { 4. How soon should } \\
\text { climate change be } \\
\text { dealt with? }\end{array}$ & 4.25 & 0.98 \\
\hline
\end{tabular}

\begin{tabular}{|l|l|l|}
\hline Question & Yes & No \\
\hline $\begin{array}{l}\text { 5. Have you changed } \\
\text { your actions, at least } \\
\text { partly, due to } \\
\text { consideration of } \\
\text { climate change? }\end{array}$ & $134(70 \%)$ & $58(30 \%)$ \\
\hline
\end{tabular}

\begin{tabular}{|l|l|l|}
\hline Question & Mean & Standard Deviation \\
\hline $\begin{array}{l}\text { 6. How much has } \\
\text { climate change been a } \\
\text { factor in changing } \\
\text { your actions? }\end{array}$ & 3.13 & 1.01 \\
\hline
\end{tabular}




\subsubsection{Results from Questions 7 - 20 Ratings of Influences on Own Actions Affecting Climate Change}

Table 5 presents the results of Questions $7-20$ from the survey. These provided data on the importance of various perceptions in shaping actions taken regarding climate change.

Table 5 Results of Survey Questions 7 -20

\begin{tabular}{|l|l|l|}
\hline Question & Mean & Standard Deviation \\
\hline $\begin{array}{l}\text { 7. The monetary cost of } \\
\text { changing my actions }\end{array}$ & 3.07 & 1.05 \\
\hline $\begin{array}{l}\text { 8. The availability of options } \\
\text { for change }\end{array}$ & 3.32 & 1.06 \\
\hline $\begin{array}{l}\text { 9. The inconvenience of } \\
\text { options for change }\end{array}$ & 2.88 & 0.95 \\
\hline $\begin{array}{l}\text { 10. Fitting changes in with } \\
\text { family and others }\end{array}$ & 2.85 & 0.99 \\
\hline $\begin{array}{l}\text { 11. Lack of knowledge about } \\
\text { possible changes I can make }\end{array}$ & 3.08 & 1.01 \\
\hline $\begin{array}{l}\text { 12. Uncertainty about the } \\
\text { best option to contribute to } \\
\text { reducing climate change }\end{array}$ & 3.09 & 1.06 \\
\hline $\begin{array}{l}\text { 13. Uncertainty as to whether } \\
\text { climate change is a } \\
\text { significant problem }\end{array}$ & 2.57 & 1.10 \\
\hline $\begin{array}{l}\text { 14. The feeling that climate } \\
\text { change is too big for my } \\
\text { actions to have an impact }\end{array}$ & 2.74 & 1.17 \\
\hline $\begin{array}{l}\text { 15. The feeling that my } \\
\text { actions will not affect the } \\
\text { outcome of climate change }\end{array}$ & 2.73 & 1.22 \\
\hline $\begin{array}{l}\text { 16. The feeling that my } \\
\text { contribution is just a drop in } \\
\text { the ocean and so is } \\
\text { insignificant }\end{array}$ & 2.75 & 1.21 \\
\hline $\begin{array}{l}\text { 17. Feeling that other } \\
\text { individuals will not change } \\
\text { their actions even if I do }\end{array}$ & 2.74 & 1.25 \\
\hline $\begin{array}{l}\text { 18. Unfairness associated } \\
\text { with bearing the cost of } \\
\text { change whilst others do not }\end{array}$ & 2.70 & 1.25 \\
\hline $\begin{array}{l}\text { 19. Other countries or people } \\
\text { not taking equivalent action } \\
\text { currently }\end{array}$ & 2.92 & 1.31 \\
\hline $\begin{array}{l}\text { 20. Looking foolish due to } \\
\text { being the only one to change } \\
\text { actions }\end{array}$ & 1.80 & 1.00 \\
\hline
\end{tabular}


On ratings of influences on one's own actions Availability of Options for Change was consistently ranked more influential than the next most influential option $(t$-test $p<0.03)$. Uncertainty about the best option for change was not ranked significantly higher than Lack of knowledge about the possible changes I can make $(t$-test $p<0.85)$ and together these two factors are second equal in ranking. Looking foolish due to being the only one to change actions is rated as the least influential item. The difference between it and the next least influential item, uncertainty about the significance of climate change is found to be significant ( $t$-test $p<.00)$.

\subsubsection{Composite Variables}

Tables 6 and 7 provide data on composite variables that were created out of various questions from the survey.

Table 6 Composite Variable Perceived Risk

\begin{tabular}{|l|l|l|l|}
\hline Composite Variable & $\begin{array}{l}\text { Composite of } \\
\text { Questions: }\end{array}$ & Mean & $\begin{array}{l}\text { Standard } \\
\text { Deviation }\end{array}$ \\
\hline Perceived Risk & 3,4 & 4.04 & 0.89 \\
\hline
\end{tabular}

Table 7 Composite Variables from Questions 7 - 20

\begin{tabular}{|l|l|l|l|}
\hline Composite Variable & $\begin{array}{l}\text { Composite of } \\
\text { Questions: }\end{array}$ & Mean & $\begin{array}{l}\text { Standard } \\
\text { Deviation }\end{array}$ \\
\hline Option Difficulty & $7,8,9,10$ & 3.03 & 0.74 \\
\hline Option Uncertainty & 11,12 & 3.09 & 0.92 \\
\hline Confusion & $11,12,13$ & 2.91 & 0.83 \\
\hline Powerlessness & $14,15,16$ & 2.74 & 1.11 \\
\hline Commons Dilemma & $17,18,19$ & 2.79 & 1.07 \\
\hline
\end{tabular}

A number of individual items were combined into composite variables based on their conceptual similarities (see Table 7). Option Difficulty and Option Uncertainty are not shown to be significantly different from one another $(t$-test $p<0.40)$, but are shown to be significantly higher rated (more influential) than Powerlessness and Commons Dilemma ( $t$-test $p<0.01$ and 0.00 respectively). Powerlessness and Commons Dilemma are not shown to be significantly different $(t$-test $p<0.48)$. 


\subsubsection{Correlations}

Table 8 Correlations from Questionnaire Data

\begin{tabular}{|c|c|c|c|c|c|c|c|c|c|c|}
\hline 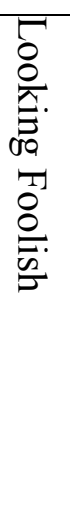 & 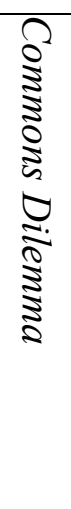 & 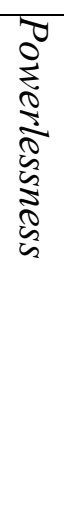 & 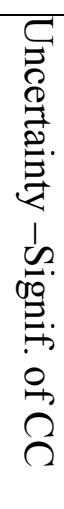 & 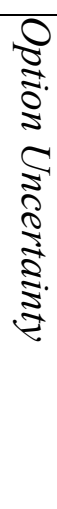 & 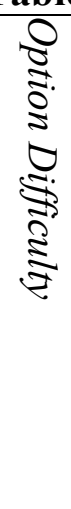 & 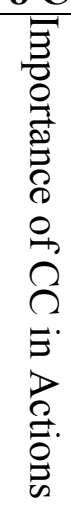 & 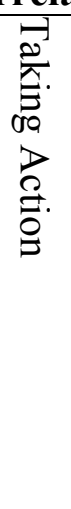 & 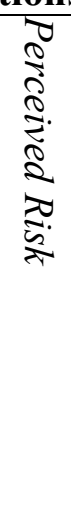 & 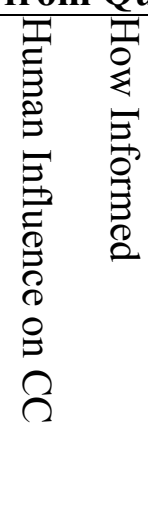 & \\
\hline$\dot{\circ}_{8}^{\prime}$ & $\dot{\sigma}_{*}^{\prime}$ & $\begin{array}{l}\dot{N}^{\prime} \\
\sigma \\
* \\
* \\
*\end{array}$ & $\dot{\sigma}_{*}^{\prime}$ & $\begin{array}{l}\dot{N}_{\alpha}^{\prime} \\
* \\
* \\
*\end{array}$ & is & $\begin{array}{l}\text { N } \\
* \\
*\end{array}$ & $\dot{\sigma}$ & $\underset{*}{\stackrel{*}{\sim}}$ & $\underbrace{}_{*}$ & How Informed \\
\hline$\dot{\circ}$ & 용 & $\dot{1}$ & $\dot{\bar{u}}_{*}^{\prime}$ & $\begin{array}{l}\ddot{\sigma} \\
* \\
*\end{array}$ & $\begin{array}{l}\underset{N}{*} \\
*\end{array}$ & $\begin{array}{l}\dot{w} \\
* \\
* \\
*\end{array}$ & $\begin{array}{l}\underset{\infty}{\infty} \\
\stackrel{*}{*} \\
*\end{array}$ & $\begin{array}{l}\stackrel{\sim}{N} \\
* \\
* \\
*\end{array}$ & - & Human Influence on CC \\
\hline$\dot{\circ}$ & $\dot{\omega}$ & $\dot{8}$ & $\dot{\sigma}_{*}^{\prime}$ & $\underset{*}{*}$ & $\underset{N}{\stackrel{N}{*}}$ & $\begin{array}{l}w_{0} \\
* \\
* \\
*\end{array}$ & $\begin{array}{l}\stackrel{\oplus}{ \pm} \\
\stackrel{*}{*} \\
*\end{array}$ & - & & Perceived Risk \\
\hline$\stackrel{\prime}{二}^{\prime}$ & $\begin{array}{l}\dot{N}^{\prime} \\
* \\
* \\
*\end{array}$ & $\begin{array}{l}\dot{1} \\
\dot{*} \\
* \\
*\end{array}$ & $\dot{\infty}$ & ம் & $\dot{i}_{*}$ & $\frac{Z}{>}$ & - & & & Taking Action \\
\hline$\dot{I}^{\prime}$ & $\dot{0}$ & 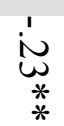 & $\dot{I}^{\prime}$ & i & $\underset{\sim}{\sim}$ & - & & & & Importance of $\mathrm{CC}$ in Actions \\
\hline$\dot{\omega}$ & $\begin{array}{l}\underset{*}{N} \\
* \\
*\end{array}$ & 巨 & $\dot{\omega}$ & $\begin{array}{l}w \\
\sigma \\
* \\
* \\
*\end{array}$ & - & & & & & Option Difficulty \\
\hline $\begin{array}{l}\overrightarrow{6} \\
* \\
*\end{array}$ & $\frac{i \omega}{*}$ & $\begin{array}{l}\underset{+}{+} \\
\stackrel{*}{*} \\
*\end{array}$ & $\begin{array}{l}\underbrace{}_{0} \\
* \\
* \\
*\end{array}$ & • & & & & & & Option Uncertainty \\
\hline $\begin{array}{l}\underset{\sim}{\sim} \\
\underset{*}{*} \\
* \\
*\end{array}$ & $\begin{array}{l} \pm \\
\forall \\
* \\
*\end{array}$ & $\stackrel{\stackrel{*}{*}}{\stackrel{*}{*}}$ & - & & & & & & & Uncertainty - Significance of CC \\
\hline $\begin{array}{l}\text { No } \\
* \\
* \\
*\end{array}$ & $\begin{array}{l}\text { ஸे } \\
* \\
* \\
*\end{array}$ & - & & & & & & & & Powerlessness \\
\hline $\begin{array}{l}\omega_{\infty} \\
* \\
* \\
*\end{array}$ & - & & & & & & & & & Commons Dilemma \\
\hline - & & & & & & & & & & Looking Foolish \\
\hline
\end{tabular}


Table 8 provides the results of analysis of survey data for correlations between various factors. Where relevant, composite variables are used instead of non-composite variables.

\section{Perception of How Informed about Climate Change}

Option Uncertainty and Powerlessness show the strongest associations with How Informed about climate change individuals consider themselves. Both show negative correlations which are low but still significant at the 0.001 level. For example respondents stating that they are well informed about climate change are less likely to indicate a lack of knowledge about possible changes they can make and less likely to profess uncertainty about the best option to contribute to reducing climate change. Similarly respondents considering themselves well informed on climate change are less likely to consider climate change too big for their actions to have an impact. Perceived Risk has the third strongest correlation with How Informed, showing a low positive relationship significant at the .01 level. Those considering themselves well informed on climate change are more likely to see climate change as a severe and urgent issue.

\section{Taking Action on Climate Change}

The strongest association with whether individuals have taken action is Perceived Risk. Perceived Risk has a moderate correlation with Taking Action that is significant. Thus individuals who consider the risks associated with climate change to be high are more likely to have taken action than those who consider these risks low. Human Influence on Climate Change and Commons Dilemma have the second strongest associations with Taking Action and both are significant. The correlation between Taking Action and Human Influence on Climate Change is positive, meaning individuals who believe climate change is mostly caused by humans are more likely to have taken action. The correlation between Taking Action and Commons Dilemma is negative and those who rate Commons Dilemma highly are less likely to have taken action on climate change.

\section{Importance of Climate Change in Actions Taken}

The correlation with Perceived Risk is the strongest association with Importance of Climate Change in Actions found. It is a moderate positive correlation and significant. This means that those who believe climate change has a high risk associated with it are more likely to rate climate change as an important factor when changing behaviour. The second strongest association is a moderate positive correlation with Human Influence on Climate Change, which is significant. Thus those who believe humans influence climate change to a significant degree are 
more likely to rate climate change highly as an important factor when changing behaviour. How Informed, Powerlessness and Option Difficulty all show similar levels of association with Importance of Climate Change in Actions and all are significant. Powerlessness shows a negative correlation while the other two show positive correlations. Those who consider themselves powerless are less likely to consider climate change important in changing their actions. Those who consider themselves well informed or consider the difficulties of change to be higher are more likely to consider climate change important in changing their actions.

\section{Powerlessness}

Powerlessness and Commons Dilemma show a strong, positive correlation. This is the strongest correlation with Powerlessness shown in this survey. A moderate, positive correlation with Uncertainty about Significance of Climate Change is the second strongest association. A moderate positive correlation with Option Uncertainty is the third strongest. These three relationships are all significant. These correlations mean that those who consider themselves powerless to effect the outcome of climate change are more likely to also feel the commons dilemma is important and feel uncertainty about both options and the importance of climate change are important. A fourth correlation of interest is the moderate, negative and highly significant relationship with Importance of Climate Change in Actions. This means that those who consider themselves powerless are less likely to place importance on climate change in any behavioural change.

\section{Commons Dilemma}

The correlation with Powerlessness is the strongest association with Commons Dilemma found. It is a strong positive correlation and is significant. For example, those who rate Powerlessness highly are more likely to rate Commons Dilemma high also. The second strongest association is a moderate positive correlation with Uncertainty about Significance of Climate Change and is highly significant. The third strongest association is a moderate positive correlation with Option Uncertainty, and is significant. Higher ratings of both Uncertainty about Significance of Climate Change and Option Uncertainty are both associated with higher ratings of Commons Dilemma. 


\section{Other Correlations}

A high positive correlation between Perceived Risk and Human Influence on Climate Change was found. This result is significant. It is the strongest correlation uncovered between any variables in the questionnaire. It suggests that respondents who consider human activity contributes to climate change are much more likely to consider climate change an urgent and severe problem. Also highly significant is the moderate positive correlation, $.46^{* * *}$, between Availability of Options for Change and Monetary Cost of Changing my Actions (not shown in Table 8). This indicates that those individuals who consider the Availability of Options for Change a constraining factor are also more likely to consider that the financial cost is a significant barrier to change also. A moderate positive correlation between Looking Foolish and Commons Dilemma was found and is significant. No significant correlation was found between Importance of Climate Change in Actions and Commons Dilemma. This indicates that those who consider the Commons Dilemma to be important are no more likely than those who do not to rank climate change as a strong factor in changing their actions.

\subsubsection{Regression Analyses}

Tables 9, 10, 11 and 12 provide the results of regression analysis of various items from the survey. Where relevant composite variables were used instead of non-composite variables. For the regression analyses, Perceived Risk and Human Influence on Climate Change were combined into one variable. This is based on two factors: The two items are strongly associated, possibly representing a degree of conflation on the part of the individual (see section 8.5.1). The two factors are so strongly associated that each greatly reduces the predictive power and significance of the other in regression analysis. Combining the two variables thus allows a more appropriate analysis than does the inclusion of both separately. 
Table 9 Simultaneous Regression Analysis for Socio-demographic and Other Factors predicting Taking Action

\begin{tabular}{|l|r|r|l|l|}
\hline \multirow{2}{*}{ Variable } & \multicolumn{3}{|c|}{ Unstandardised Coefficients } & \multicolumn{1}{l|}{ Standardised Coefficients } \\
\cline { 2 - 5 } & $\mathrm{B}$ & & Std. Error B & \multicolumn{1}{l|}{$\beta$} \\
\hline Risk and Human Influence & .21 & .04 & $.40^{* * *}$ \\
\hline Commons Dilemma & -.14 & .04 & $-.35^{* * *}$ \\
\hline Income & -.07 & .03 & $-.15^{*}$ \\
\hline Option Difficulty & .07 & .05 & .12 \\
\hline Confusion & .05 & .04 & .10 \\
\hline Age & .03 & .02 & .10 \\
\hline Gender & .08 & .07 & .09 \\
\hline How Informed & .04 & .04 & .08 \\
\hline Qualification & .04 & .04 & .07 \\
\hline Powerlessness & -.00 & .04 & -.01 \\
\hline Looking Foolish & -.00 & .03 & -.01 \\
\hline
\end{tabular}

Table 10 Simultaneous Regression Analysis for Socio-demographic and Other Factors predicting Importance of Climate Change in Actions Taken

\begin{tabular}{|c|c|c|c|}
\hline \multirow{2}{*}{ Variable } & \multicolumn{2}{|c|}{ Unstandardised Coefficients } & Standardised Coefficients \\
\hline & $\mathrm{B}$ & Std. Error B & $\beta$ \\
\hline Risk and Human Influence & .58 & .14 & $.37 * * *$ \\
\hline Powerlessness & -.26 & .10 & $-.26 * *$ \\
\hline Age & .21 & .07 & $26^{* *}$ \\
\hline Option Difficulty & .34 & .14 & $.22 *$ \\
\hline Commons Dilemma & .18 & .10 & .18 \\
\hline Looking Foolish & -.11 & .10 & -.11 \\
\hline How Informed & .12 & .11 & .10 \\
\hline Qualification & -.10 & .11 & -.07 \\
\hline Gender & .08 & .18 & .04 \\
\hline Confusion & .03 & .13 & .02 \\
\hline Income & .02 & .09 & .02 \\
\hline
\end{tabular}


Table 11 Simultaneous Regression Analysis for Socio-demographic, Background and Influence Rating Variables Predicting rating of Powerlessness

\begin{tabular}{|c|c|c|c|}
\hline \multirow[t]{2}{*}{ Variable } & \multicolumn{2}{|c|}{ Unstandardised Coefficients } & \multirow{2}{*}{$\begin{array}{l}\text { Standardised Coefficients } \\
\beta\end{array}$} \\
\hline & $\mathrm{B}$ & Std. Error B & \\
\hline Commons Dilemma & .54 & .07 & $.53 * * *$ \\
\hline How Informed & -.21 & .09 & $-.17 *$ \\
\hline Confusion & .20 & .10 & $.15^{*}$ \\
\hline Age & .08 & .05 & .10 \\
\hline Difficulty & -.07 & .10 & -.05 \\
\hline Gender & -.10 & .15 & -.05 \\
\hline Income & -.03 & .07 & -.03 \\
\hline Looking Foolish & -.01 & .08 & -.00 \\
\hline Qualification & .01 & .08 & .00 \\
\hline Risk and Human Influence & .00 & .09 & .00 \\
\hline
\end{tabular}

Table 12 Simultaneous Regression Analysis for Socio-demographic, Background and Influence Rating Variables Predicting rating of Commons Dilemma

\begin{tabular}{|c|c|c|c|}
\hline \multirow[t]{2}{*}{ Variable } & \multicolumn{2}{|c|}{ Unstandardised Coefficients } & \multirow{2}{*}{$\begin{array}{l}\text { Standardised Coefficients } \\
\beta\end{array}$} \\
\hline & $\mathrm{B}$ & Std. Error B & \\
\hline Powerlessness & .48 & .06 & $.50 * * *$ \\
\hline Looking Foolish & .19 & .07 & $.18 * *$ \\
\hline Confusion & .24 & .09 & $.18^{*}$ \\
\hline Age & -.11 & .05 & $-.14 *$ \\
\hline Difficulty & .15 & .10 & .10 \\
\hline Income & -.07 & .07 & -.07 \\
\hline How Informed & .06 & .08 & .05 \\
\hline Qualification & .05 & .08 & .04 \\
\hline Gender & -.03 & .14 & -.01 \\
\hline Risk and Human Influence & -.03 & .08 & .00 \\
\hline
\end{tabular}




\section{Discussion}

\subsection{Focus Groups}

\subsubsection{General Findings}

Participants showed a diverse set of beliefs, levels of knowledge and opinions regarding climate change. A review of all of these allows for some conclusions to be drawn as to how at least some of the public view climate change.

Across the range of topics covered in the focus groups there was a tendency for participants to simplify issues down to what they perceived to be the single most significant factor. For instance, those who provided a specific cause for climate change chose to name carbon dioxide from industry. There was little to no acknowledgement of the more diverse causes such as deforestation or methane. When providing examples of those responsible for causing climate change, either China or the USA were frequently named. Smaller more numerous contributors at the country, organisation or personal levels were not generally given. Both of these examples illustrate cases in which just the perceived largest single factor was named.

Simplification could be seen to represent a means of avoiding confusion when considering decision making. By simplifying the issue to one or two causes and effects it is more easily grasped than an issue which is more complex. Other possible causes may be that individuals simply lack the knowledge about more diverse answers, or, that within the context of a focus group they prefer to give only limited rather than complete answers. One implication of this simplifying of climate change issues is that it will make rational decision making difficult due to the absence of the prerequisite knowledge. This might lead to psychological barriers to change having a heightened level of importance over factors such as cost.

Another occurrence noted amongst the focus group participants was the apparent lack of distinction between climate change and other environmental issues. This was evident at several points during the discussion. Initial talk of the causes frequently led to industry being named, a cause so broad that it could cover all manner of environmental problems from acid rain to water pollution. There was also confusion between climate change and the ozone hole, a misunderstanding frequently found in studies of public awareness of climate change (Futerra, 2004; Ungar, 2000). Furthermore when participants were asked what actions they took to reduce 
their contribution to climate change they frequently stated composting or recycling. Both of these actions have, at best, weak connections to climate change and are generally considered as remedies for other problems such as resource depletion or landfill overuse. These cases illustrate a tendency to not deal with climate change, either conceptually or in actions, as separate from general environmental problems. This may be due to factors such as the limited time available to the general public to engage in actively learning about environmental problems, thus constricting a clear understanding of the distinctions. Overall, this finding is supported by the observation that, regarding most questions, the majority of participants in each group had little or nothing to add to the discussions, suggesting prior consideration of the topics, necessary to the formation strong opinions, had not taken place.

\subsubsection{Powerlessness}

Several questions during the focus group stage examined points of relevance to powerlessness. Most participants believed that they could take more actions to reduce their contribution to climate change. When discussion then moved to what the reasons for not taking action were, all answers centred on time, money, inconvenience, lack of knowledge and most often of all, unavailability of choices. These options represent, in varying degrees, powerlessness over behavioural control as used in Ajzen's (1991) theory of planned behaviour. This is especially true of the last and most cited reason, availability of choices. This thesis examines powerlessness in the form of control over outcomes. Neither this reason, nor the commons dilemma, were given as reasons for inaction.

This does not mean that powerlessness over outcomes is not a reason for inaction. Instead several processes may account for the absence of it as a stated reason. Firstly individuals may not fully understand the reasons behind their choices and simply state what they believe is important i.e. erroneously state the unavailability of options as important when in fact it is not. Secondly they might feel some measure of guilt at not taking action and prefer to state reasons that place it outside of their control and in so doing reduce guilt. Thirdly, in section 8.1.1, discussion covered what appeared to be simplification of issues down to the factor perceived to be the most important by participants in the focus groups. It is consistent with this last point that individuals providing reasons for not taking action should fail to state those reasons that, though possibly important, are considered secondary. 
Powerlessness was mentioned when individuals were asked how they felt in the face of messages about the global scale of climate change. Participants reported feeling powerless and small in the face of an issue of such scale. But those who gave more elaborate answers talked of the scale of their actions compared not with the global size of the problem but instead in relation to much larger contributors to climate change such as China or industry. These findings suggest that individuals do feel powerless to deal with climate change. It also suggests that much of the perception of powerlessness stems not from the sheer scale of climate change but rather from a view of the individual's size compared with much larger contributors.

Powerlessness was specifically focused upon by questioning how individuals would react if they could know for certain that taking a particular course of action would result in some lessening of climate change. Responses across all groups were very similar on this. If they could know for sure that their contribution would make a difference then they would be greatly encouraged to take action. This suggests that individuals do take into account perceptions of personal efficacy when decision making.

Responses across the focus groups indicate that while not either a crucial or well recognized reason for inaction, the perception of being powerless to affect climate change is present amongst the public. The perception of powerlessness appears to be due to beliefs that actions an individual can take are too small to make a tangible difference. They are considered to be too small largely because of perceptions they are dwarfed by the actions of much larger contributors, e.g. China, rather than the actual size of climate change as a problem e.g. rising sea levels.

\subsubsection{Commons Dilemma}

When discussing voluntary schemes to mitigate climate change two participants believed that parts of society (a majority according to one and minority according to the other) would fail to take part in any such scheme. This shows some recognition of free-riding as a problem that undermines the provision of a public good, making individuals powerless to achieve an outcome. When asked explicitly how they would react to free-riding some participants indicated that they would continue to contribute whilst others stated they would contribute less or consider not contributing at all.

These results suggest that the commons dilemma is an issue that the public considers to be important when dealing with climate change. A majority of participants who answered a 
hypothetical question on free-riding stated that they would still continue to contribute in the presence of free-riding. This should not be taken to mean that most in the wider public will act in this manner. As already noted focus groups are not representative of the whole population due to self selection. Furthermore responses to this hypothetical answer were neither anonymous nor ongoing over a long or indefinite period of time, both factors known to decrease contributions (Fox \& Guyer, 1978; Isaac et al., 1985).

The commons dilemma is a factor recognized by some in the public as an important part of considerations about contributing to climate change mitigation. While many focus group participants did not find the commons dilemma crucial to a hypothetical contribution this result cannot be taken as conclusive due to the inherent limitations of focus group data collection.

\subsection{Survey Results}

\subsubsection{Ratings}

The average ratings of factors measured with questions $7-20$ in the survey (on possible reasons for inaction) provide an interesting set of findings (see Table 5). That the Availability of Options should be rated as the most influential item in determining behaviour is a notable finding. A high rating of this item indicates that individuals feel their choices are to a significant extent constrained by the options open to them. This finding is similar to the statements of individuals during focus groups undertaken for this research and by others (Lorenzoni et al., 2007). The reason why this factor is considered so important may be twofold. First, if options for change are genuinely not available, then the rating of this item will logically indicate that option availability is very influential. But based upon existing evidence there are likely to be more complex reasons behind the high rating of this option. It has been found that individuals justify commons dilemma defections by labelling themselves powerless to affect an outcome even when the contrary is true (Kerr \& Kaufman-Gilliland, 1997). This is particularly prevalent when confusion about either the issue or expected response occurs (Weber et al., 2004). At this point it is necessary to draw a distinction between powerlessness as used by Kerr \& Kaufman-Gilliland (1997) and that measured by the item Availability of Options. In the research by Kerr \& Kaufman-Gilliland (1997) powerlessness refers to [its occurrence in the form of] low personal efficacy as used in Stern's (2000) Values-Beliefs-Norms theory of behaviour. That is, individuals may define themselves as powerless to have any effect upon a desired outcome. In contrast, the item 
Availability of Options is a measure of powerlessness in the sense of Ajzen's (1991) theory of planned behaviour, i.e. powerlessness to choose a desired option for reasons beyond the individual's control. Research by Kerr \& Kaufman-Gilliland (1997) did not examine whether this form of powerlessness is used to justify inaction in a commons dilemma. This suggestion cannot yet be empirically supported, but it does seem plausible that powerlessness in regard to perceived behavioural control is also given as a reason for defection in commons dilemmas when confusion regarding the situation is high.

This response to confusion also fits with behaviour regarding norm confusion predicted by Schwartz and Howard's (1981) theory of normative decision making. According to this model, individuals respond to norm confusion that results in inaction by, among other responses, denying their personal ability to make a change. If a process is occurring whereby individuals justify inaction by denying the ability to make a change then a high rating of Availability of Options is likely even when options are in actual fact available. Several lines of evidence in the current findings back this up. Firstly, those who rated Confusion highly were slightly more likely to also rate Availability of Options highly. This finding supports the comparison with Schwartz and Howard's (1981) norm confusion model. Secondly, those who rated Availability of Options highly were moderately more likely to also rate Monetary Cost of Changing Actions highly $\left(r=0.46^{* * *}\right)$. If monetary costs are considered to be preventing change, then that means that there are options for change open to the individual. Thus the availability of options would have a low influence rating because options for change do exist, albeit that they are too expensive. This would result in a negative correlation between the two items, the opposite of what is observed here. Finally, despite the importance placed upon Availability of Options as a factor limiting behavioural change, those who rate it highly are more likely to have taken action on climate change and consider climate change more important in their actions.

Evidence from this research supports a hypothesis that individuals respond to commons dilemmas by feeling unable make a change at the individual level. This may account for some of the perceived importance of availability of options both within focus groups and the survey.

Due to their conceptual similarities, the second and third highest rated variables, Uncertainty about the best option for change and Lack of knowledge about possible changes, were grouped together as the composite variable Option Uncertainty (see Table 7). From a logical point of view one might not expect a high rating for Option Uncertainty. For one, 
delaying a decision until the best option is known is counter to actually achieving the desired result. If one is interested in reducing one's contribution to climate change then any option which has a positive effect, even if not the best, is still worth considering. Waiting for better information about the best option and remaining with the status quo does not lead to any reduction in one's contribution to climate change. A second consideration is that given the amount of information available to individuals on options for change either passively (e.g. billboards) or actively (e.g. a search on the internet), it seems implausible that individuals could have little or no knowledge of possible ways they might take actions, at least in any such levels that would lead this to be rated one of the most influential reasons in deciding their actions.

\subsection{Powerlessness Findings from Questionnaire}

Despite Powerlessness showing a weak correlation with Taking Action (see Table 8) there is no relationship apparent when regression analysis is conducted (see Table 8). This suggests that any effect of powerlessness is secondary to one or more of Risk and Human Influence, Commons Dilemma or Income. The dominant, overshadowing effect of powerlessness on taking action is likely to be Commons Dilemma, on the basis of the moderate correlation $(r=0.62 * * *)$ between Commons Dilemma and Powerlessness. Confirming this, removal of the Commons Dilemma variable from the regression analysis led to Powerlessness becoming a significant predictor of having taken action on climate change $\left(\beta=-0.18^{*}\right)$. Removal of the other significant explanatory variables and inclusion of Commons Dilemma led only to insignificant findings for the importance of Powerlessness with regard to having taken action.

The correlations between Powerlessness and other variables (see Table 8) suggest that though it may be seen as influential in individuals behaviour to reduce climate change, it is neither a large nor important factor in determining whether individuals have taken action. However this conclusion may mask the important role of Powerlessness. It is the only factor found to be associated with a lower level of Importance of Climate Change in Actions (see Table 10); in combination these findings suggests that although individuals are no more or less likely to have taken action on climate change if they feel powerless (see Table 9), the more powerless an individual feels the less likely they are to consider climate change an important factor when changing their behaviour. In effect, other reasons for changing behaviour eclipse climate change as a motivator. 
A relationship between Uncertainty about the significance of climate change and Powerlessness was predicted, though not its strength. It is in line with theory (Anderson, 2003; Schwartz \& Howard, 1981) and findings by other researchers (Kaplan, 2000) that suggested that uncertainty and incomplete information lead to indecision and also, indirectly to powerlessness.

The relationship between How informed and Powerlessness (see Table 11), indicating that those who feel less informed about climate change are more likely to feel powerless is expected based upon the results of Haller and Hadler (2008). The results of Haller and Hadler (2008) showed a similar relationship between general environmental knowledge and powerlessness. The results in this study relating to How Informed are also consistent with the Option Uncertainty results. Both variables relate to Powerlessness in such a way as to suggest that increased knowledge about climate change in general and options for taking action reduce powerlessness.

\subsection{Powerlessness and the Commons Dilemma}

Those who rate the Commons Dilemma items as highly influential on their actions are much more likely to also rate Powerlessness highly (see Table 12). Predictions about the closeness of the relationship between Commons Dilemma and Powerlessness were not made but its presence is consistent with findings from the literature showing a relationship between these two perceptions. Based on that literature a possible explanation can be proposed. The consideration of the actions of others has been found to be of importance when individuals are deciding upon contributions in resource allocation commons dilemmas (Wade-Benzoni et al., 1996). In such situations the commons dilemma nature of the problem acts to make people believe their contribution will be ineffective at achieving change because others will not contribute to a solution. Evidence to support this was found during the focus group research conducted both for this research and by others (Stoll-Kleemann et al., 2001). Participants perceived an inability to achieve a desired outcome through voluntary or individual actions because of the failure of others to carry out similar actions.

\subsection{Commons Dilemma}

While not showing the strongest correlation with Taking Action found in this study, Commons Dilemma does show the strongest negative relationship. This supports the hypothesis that the commons dilemma is associated with lowered action on climate change. As the strongest negative association with Taking Action it is of particular interest for any campaigns aiming to 
alter climate change related behaviour. Addressing this issue in an effort to minimise likely barriers to change that individual's face, will be of importance.

A correlation between Commons Dilemma and Uncertainty about the significance of climate change was expected based on the review of literature (Biel \& Gärling, 1995; Kortenkamp \& Moore, 2006). Review of the literature had not led to any predictions regarding a relationship between Commons Dilemma and Option Uncertainty. However, if the rating of Option Uncertainty serves as a proxy for degree of confusion on the matter, as is suggested in Section 8.8 then the correlation between Option Uncertainty and Commons Dilemma is to be expected based upon the relationship between confusion and the commons dilemma. In commons dilemmas individuals are less likely to contribute when confusion is high. This is due to the uncertainty about both the expected response and the response of others that this leads to. Thus the commons dilemma would be considered more highly by those who feel confusion about the issue of climate change.

\subsection{Perceived Risk}

Perceived Risk is found to have the strongest relationship with Action Taken of any variable (see Table 8). Bord et al. (2000) and Haller and Hadler (2008) have found a similar correlation, giving perceived risk an important relationship with taking action. This relation is also consistent with Stern's (2000) Values-Beliefs-Norms framework of environmental behaviour. According to this model, evaluations of risk and threats to valued items form an important step in a framework predicting environmental behaviour. A high rating of Perceived Risk is therefore in line with previous research on risk and behaviour (Haller \& Hadler, 2008; Leiserowitz, 2006).

The correlation between ratings of Perceived Risk (considerations of severity and urgency of the problem of climate change) and Human influence on climate change was the strongest of any found in the survey $\left(r=0.72^{* * *}\right)$. The strength of this finding is interesting for it is possible that an individual might hold the opinion that climate change is entirely natural in origin and still think it a large risk or see climate change as human induced and a small risk. The strong correlation indicates that either of those options is uncommon. This may represent some degree of conflation of the two variables on the part of individuals. It might also be related to individuals attempting to deny the riskiness of climate change and rationalising this on the 
grounds that climate change is not a matter of human influence. Conversely others may see climate change as risky and human driven.

This finding is an interesting and unexpectedly clear finding. Previous study on the subject by Kellstedt et al. (2008) found that when individuals had greater confidence in the science of climate change they felt less responsible for the problem and subsequently rated the risk lower. Although the rating of Human influence on climate change in the present study is not entirely interchangeable with the rating of certainty in the science used by Kellstedt et al. (2008), it is broadly comparable. These authors measured how much trust individuals placed in scientists who gave information about climate change. It is likely that information from scientists is in line with scientific literature on the causes of climate change, in which a consensus about the anthropogenic cause of current climate change exists (Oreskes, 2004). Therefore individuals who trust information from scientists would be expected to also rate the human influence on climate change, the variable used in the present study, highly. In order to explain the difference between the conflicting results of this study and those of Kellstedt et al. (2008) it would be of interest to examine the quality of information possessed by individuals in both studies. This is particularly true given that the study by Kellstedt et al. (2008) took place in the United States, a country with a highly active climate change 'denial' industry (Jacques et al., 2008) and below average knowledge of climate change when compared to the rest of the industrialised world (Brechin, 2003). These factors increase the likelihood that those participating in the study by Kellstedt et al. (2008) possess incorrect information on climate change.

In the present study a high rating of the human influence on climate change should indicate greater confidence in the science and also possibly some sense of responsibility for the problem. Thus if the relationship shown by Kellstedt et al. (2008) was to be reflected in the present study, it would be expected that the correlation between Human influence on climate change and Perceived Risk (even if different in strength to that of Kellstedt et al. (2008)) would still be negative, this is completely different to the actual results $(r=0.72 * * *)$. Logically, it is plausible that individuals with greater knowledge of the science of climate change also consider the risks higher if the impression given from their information sources is that of a comparatively severe problem. 


\subsection{How Informed}

Ratings of How Informed participants consider themselves to be provided a set of correlations with other variables that was similar to findings from the literature. A higher rating of the risks associated with environmental problems has been observed when knowledge of the environment is higher (Haller \& Hadler, 2008). The research by Haller and Hadler examined general environmental risks as opposed to specific ones. The results of this survey provide support for the hypothesis that climate change is affected in a similar manner.

Of importance is the relationship between rating of How Informed participants feel and Taking Action. Fundamental to the operation of the knowledge deficit model underlying many climate change communications (Barr \& Gilg, 2007; Barr et al., 2001; Kellstedt et al., 2008) is the belief that greater knowledge will lead to greater action. However the correlation found is weak, suggesting that greater knowledge is not an important factor when deciding whether action is taken on climate change. On the other hand it is not a strong negative correlation, thus there is no reason to think that better informed people are less likely to have taken action on climate change.

\subsection{Other Findings}

Based on the high rating given to Option Uncertainty, one might expect high Option Uncertainty to be negatively and at least moderately associated with action. However no relationship is found in the correlations or regression analysis. This appears to contradict the rating given to the item. Possible explanations for this include: either people are inconsistent, saying that Option Uncertainty is important but not necessarily taking no action or Option Uncertainty is a barrier but not one that might be considered 'fatal' to taking action.

Option Uncertainty is a rating of how incomplete individuals consider their information about potential changes they might make to their behaviour. An interpretation arising from the literature review for this research is that when individuals feel they have incomplete information, it is a result of confusion surrounding the issue, not necessarily an actual lack of information (Anderson, 2003; Haller \& Hadler, 2008). This interpretation would also imply that they will show higher levels of powerlessness than those who feel they have more complete information (Haller \& Hadler, 2008). It is therefore worthwhile examining the possibility that Option 
Uncertainty represents individuals' rating of how confused or uncertain they are about the entire issue of climate change as opposed to just the possible options for change.

If the rating of Option Uncertainty represents confusion about climate change then a negative correlation with the rating of How Informed and positive correlations with the ratings of Powerlessness and Commons Dilemma would be expected. If this is not the case and it does represent uncertainty about possible options, then a negative correlation with Taking Action is expected. All of the first three conditions are met: the correlations with rating of How Informed, Powerlessness and Commons Dilemma are as expected. The fourth condition is also met, in that no significant correlation between Option Uncertainty and Taking Action is found. These results, along with theory suggesting confusion will be high surrounding an issue such as climate change (Kortenkamp \& Moore, 2006), support the suggestion that Option Uncertainty is a proxy for confusion on the issue of climate change. More research into this area is necessary in order to be able to draw a strong conclusion about a possible relationship between the two variables.

It is of interest, for it is apparently counter intuitive, that the rating of the influence of Option Difficulty (cost, inconvenience, availability and fitting in with others) has a positive correlation with Taking action. One interpretation of this would be that the harder people find it to change the more likely they are to do so. On the face of it, this appears illogical. However another explanation provides a more satisfactory answer. Individuals who have taken action are more likely to have come across the barriers to change encompassed by the variable Option Difficulty than those who have not; i.e. not until beginning to take some action do the barriers such as cost become apparent. Those who take no action are less aware of difficulty barriers and instead consider the various perceptions covered by other questions to be of greater importance

\subsection{Socio-demographic Factors}

The relationship of socio-demographics with the various factors important to this study has been found to be small; only age and income showed any statistically significant relationships. This general finding of few relationships with socio-demographics was expected following the review of the literature. Stern's (2000) Values-Beliefs-Norms model does not include any such factors as significant, at least directly. Nor did the review of current understanding of perceptions of powerlessness and the commons dilemma indicate that socio-demographic factors would be important. Haller and Hadler (2008) found socio-demographic factors to be of minor importance 
when predicting powerlessness. These may be briefly summarised as those who were younger, better educated, richer or female were slightly less powerless. Kellstedt et al. (2008) however found statistically significant results only for age. These contrasted with the results of Haller and Hadler (2008) by finding that older individuals were less likely to feel powerless. The results of the present study support the finding by Kellstedt et al. (2008), showing that socio-demographics are of minor importance when predicting perceptions of powerlessness and the commons dilemma.

The relationship of income with Taking Action is of interest. The results show that those with higher incomes were slightly less likely to have taken action on climate change. It is likely that those with higher incomes would have a greater ability to choose environmentally friendly alternatives that might cost more. Instead this finding suggests that individuals do not take actions that would have a negative impact on climate change e.g. an international flight, due to cost constraints but afterwards claim that the reason or at least part of the reason that action was not taken was concern about climate change.

\subsection{Results within the Values-Beliefs-Norms Framework}

The findings from this research are consistent with the framework of environmental behaviour described by the Values-Beliefs-Norms (VBN) model (Stern, 2000).

\begin{tabular}{|c|c|c|c|c|c|}
\hline Values & \multicolumn{3}{|l|}{ Beliefs } & $\begin{array}{l}\text { Proenvironmental } \\
\text { Personal Norms }\end{array}$ & Behaviours \\
\hline \begin{tabular}{|l|} 
Biospheric \\
Altruistic \\
Egoistic \\
\end{tabular} & $\begin{array}{l}\text { Ecological } \\
\text { worldview }\end{array}$ & \begin{tabular}{|l|} 
Adverse \\
consequences \\
for valued \\
objects \\
\end{tabular} & \begin{tabular}{|l|} 
Perceived \\
ability to \\
reduce \\
threat \\
/Powerlessness
\end{tabular} & $\begin{array}{l}\text { Sense of } \\
\text { obligation to } \\
\text { take proenviron- } \\
\text { mental actions }\end{array}$ & $\begin{array}{l}\text { Activism } \\
\begin{array}{l}\text { Non-activist } \\
\text { public sphere } \\
\text { behaviours }\end{array} \\
\end{array}$ \\
\hline & & & & & $\begin{array}{l}\text { Private-sphere } \\
\text { behaviours }\end{array}$ \\
\hline $\begin{array}{l}\text { Step } \\
1\end{array}$ & $2 a$ & $2 b$ & $2 c$ & 3 & $\begin{array}{l}\text { Behaviours in } \\
\text { organisations }\end{array}$ \\
\hline
\end{tabular}

Figure 9 Values Beliefs Norms model of environmental behaviour. Adapted from Stern (2005)

According to the VBN model, what might be termed a 'rational' cost-benefit analysis or examination of applicable factors is not important in determining actual pro-environmental behaviour. In the present results, Option Difficulty, i.e. those factors with tangible considerations such as cost in time or money which would constitute a significant part of a 'rational' analysis, is not found to have a significant level of predictive power regarding taking action $(\beta=0.12)$. This 
finding supports their omission from the VBN model. However, positive support for this model of behaviour comes from the ratings of perceived risk, human influence on climate change, powerlessness and the commons dilemma. Each of these factors was rated as important relating

to one or both of the two action variables measured with survey Questions 5 and 6. Each of these corresponds to one of the beliefs present at Steps $2 \mathrm{a}-\mathrm{c}$ above. Together they encompass all the steps. Perceived Risk is contained within Step $2 b$, adverse consequences for valued objects, of the model. An ecological worldview, Step 2a, is shaped by a number of factors. One important factor is a belief in interconnections between human activities and the natural environment (Dunlap et al., 1992). An individual's rating of human influence on climate change therefore provides some indication how strongly they consider human activities and the environment to be connected. For this reason the association between both action variables and the rating of human influence on climate change is consistent with the VBN model. Powerlessness and the commons dilemma are contained within Step 2c. The relatively high correlation of these items with taking action supports their inclusion as key factors in the VBN model.

The purpose of this research was not to comprehensively assess the validity of the VBN model of environmental behaviour; therefore values and norms were not examined.

\subsection{Limitations of this Research}

The results of this study are subject to several limitations. Results of the focus groups cannot be taken to be representative of the wider population of New Zealand or even Wellington. This is due to the self-selecting sample that takes part in the focus groups. There is a tendency for those who participate to have strong opinions about the topic, a particular interest in it or simply take part for the reward. The survey is also subject to similar limitations. Constraints meant that the survey area was limited to three locations within the Wellington region and around 200 participants. There are two important limitations regarding this constraint that must therefore be noted.

Firstly, because only one region, within one country was surveyed the potential for population variation to give differing results in other regions must be recognised. Other surveys have found differences in environmental values to be significant even within comparatively similar wealthy, liberal Western democracies (Harrison et al., 1996). These differences are even more pronounced between regions with strongly differing wealth and political structures (Haller \& Hadler, 2008). 
Secondly, the socio-demographics of the group (see Table 3) show that the sample differs significantly even from the general New Zealand population. The most notable differences in socio-demographics between the sample group and the wider population of New Zealand concern income and education. The survey group had higher levels of both education and income than the wider population. The ages of those in the survey sample were also clustered around middle age bands with smaller proportions over 60 or under 20 years of age.

The effect that any of these differences would have upon the data gathered via the survey is unknown. It is possible, for example, that the proportion reporting having taken action (70\%) is higher in the sample than would be the case for the New Zealand population as a whole. Thus these results may not necessarily reflect opinions and/or associations that are present within the wider population of either New Zealand or other locations in the world.

Separate from socio-demographic or representational concerns, it must also be noted that the questionnaire was elicited self assessment. In particular, regarding questions about actions (Question 5 and 6) the limitation must be noted that the answers given may more accurately reflect intentions than actual behaviours, a finding already cited by other researchers (Stern, 1992).

\subsection{Directions for Further Research}

Results of this study indicate several lines of interest for further research.

Confusion surrounding climate change - The results of this research indicate that confusion has an important relationship with perceptions of powerlessness and the commons dilemma. This finding is supported by evidence from the literature review. Following on from this finding there are several questions of interest to furthering understanding of confusion and climate change:

What are the main causes of confusion? Reasons for confusion are likely to centre on conflicting information, the response of others and characteristics inherent to climate change. This study was not intended to determine causes of confusion.

How does confusion relate to perceptions of powerlessness and the commons dilemma?

A relationship between these two variables was found but due to the nature of this research a causal link could not be established. Based on the literature review it is expected that individuals respond to confusion by labelling themselves powerless. Research to either confirm or challenge this would be of interest. 
The importance of unavailability of options for change - This factor was consistently given as the most important factor constraining individuals from taking further action on climate change during focus groups and in surveys. This contrasts with the low importance of the item found via regression analysis. This suggests that individuals justify inaction by denying the ability to take action when in fact other reasons are instead compelling. This is a phenomenon that fits with Schwartz and Howard's (1981) model of behaviour regarding conflicting norms. Investigating if and why this occurs regarding environmental behaviour would be of interest to encouraging behavioural change.

The importance of climate change in behaviours - Much behaviour that can be considered to be reducing contributions to climate change also has co-benefits such as savings in money. These co-benefits could easily overshadow any concerns individuals have regarding climate change, these concerns might even be non-existent. Having changed behaviour individuals might then rate climate change as an important factor. Such behaviour may or may not be intentional. It means that self reported behaviours might be inaccurate at finding actual causes and levels of change. It would therefore be of interest to investigate the relative importance of climate change versus co-benefits in motivating behavioural change.

Perceptions as important first barrier to change - The results from the survey suggest that those who consider cost and other barriers important are more likely to have taken action. This finding seems counter intuitive. A possible explanation is that individuals do not consider the barriers such as cost until during and after taking action. The implication of this is that perceptions such as powerlessness initially prevent change. Not until some change is made or attempted do other barriers become apparent. Investigating whether this interpretation is true will be of importance to behaviour change campaigns for it implies that addressing perceptions is an important first step towards encouraging behaviour change. 


\section{Conclusion}

The aim of this thesis has been to evaluate perceptions of powerlessness and the commons dilemma in relation to individual action on climate change. Both of these perceptions can act as psychological barriers to change. Therefore an improved understanding of the factors associated with perceptions of powerlessness and the commons dilemma and importance of each barrier may enable campaigns aiming to encourage pro-environmental behaviour to address them. This is especially important in light of recent research suggesting that one of the most common methods of encouraging pro-environmental behaviour may actually strengthen psychological barriers, in particular powerlessness (Kellstedt et al., 2008).

Mixed method research was conducted in order to gather both qualitative and quantitative data. Financial and time constraints limited the location of the study to the Wellington region. Focus groups allowed for active discussion of the topics and informed the design of a questionnaire to collect quantitative data for statistical analysis.

Within the focus groups individuals showed a tendency to simplify issues relevant to what was perceived as the single most important component. This indicated incomplete understanding of the climate change issue; attribution of blame for climate change to large single entities and a general failure to separate climate change from other environmental problems such as ozone depletion or low hydro electricity lake levels. This confusion occurred both in terms of understanding the causes and possible solutions to climate change. When participants were asked why individual action was not taken on climate change the most important reason given was the perceived lack of options for change available. When questioned more directly, both powerlessness and the commons dilemma were found to have been given some consideration. Powerlessness appeared to be more widespread and considered in greater detail than the commons dilemma. Powerlessness appeared to be most prominent in relation to the individual's size compared to other large contributors to climate change, e.g. China, rather than catastrophic effects e.g. sea level rise. Most participants appeared not to have considered climate change and possible responses to it either in detail or separate from general action to 'save the environment'. The responses given showed similarity with those found by other researchers who have conducted focus groups on the same topic (Futerra, 2004; Stoll-Kleemann et al., 2001).

Questionnaire data indicated that individuals consider that availability of options is the most important constraining factor in terms of individual action on climate change. But when the 
data were examined with correlations and regression analysis a different picture emerged. The availability of options and other factors, such as the cost of taking action were found to be, at best, weak predictors of whether individuals took action to reduce climate change. Counter-intuitively those rating cost highly were more likely to have taken action than those rating it lower.

The survey results suggest that the perceptions of individuals about the commons dilemma and powerlessness regarding climate change are important at different stages of taking action on climate change. The commons dilemma is important when initially taking action whilst powerlessness affects the importance placed upon climate change in actions taken. The counterintuitive rating of cost and the ratings of powerlessness and the commons dilemma raises an interesting hypothesis. Individuals make initial decisions based upon perceptions such as powerlessness rather than more practical considerations such as cost. Not until individuals are taking action are they shaped by those practical considerations.

The findings of this research support the hypotheses that heightened perceptions of powerlessness and the commons dilemma are associated with lower levels of action on climate change i.e. those who rate powerlessness and the common dilemma highly are less likely to take action and if they do, they are more likely to consider climate change less important in their actions. The hypothesis that a heightened sense of risk about climate change is associated with raised levels of powerlessness and a lower level of action is challenged. The findings of this study indicate that the opposite is true. Those who consider the risks of climate change to be high are less likely to consider themselves powerless and more likely to take action. The hypotheses that a high level of information on climate change is associated with lesser perceptions of climate change risk and high perceptions of powerlessness are challenged too. This study found that those who considered themselves more informed are more likely to rate climate change as riskier, more likely to see it as an urgent issue and feel less powerless regarding their ability to mitigate it.

In combination the findings show that stronger perceptions of powerlessness and the commons dilemma are associated with lower levels of action regarding climate change. The perceived risk of climate change and the perceived level of human influence on climate change are however the factors most strongly predictive of having taken action. The findings of this research generally provide support for the knowledge-deficit model of behaviour change. 


\section{Appendix 1- Focus Group Documents Focus Group Information Sheet \\ TE WHARE WĀNANGA O TE ŪPOKO O TE IKA A MĀUI

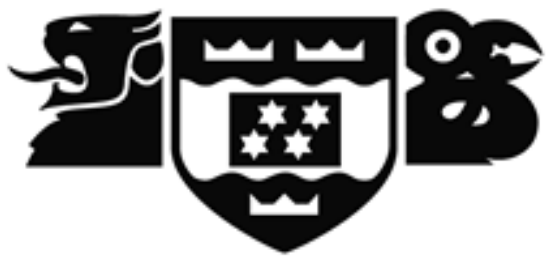

Information Sheet for Focus Group Participants

Christopher Aitken

MEnvStud Student

aitkenchri@student.vuw.ac.nz
Ralph Chapman

Associate Professor

ralph.chapman@vuw.ac.nz
John McClure

Associate Professor

john.mcclure@vuw.ac.nz 463-6047

What is the purpose of this research?

- This research will enable us to examine the role of powerlessness in influencing people's actions about climate change

Who is conducting the research?

- Christopher Aitken in the School of Geography, Environment and Earth Sciences. Supervised by Associate Professor Ralph Chapman of the School of Geography, Environment and Earth Sciences and Associate Professor John McClure of the School of Psychology. This research has been approved by the University ethics committee

What is involved if you agree to participate?

- If you agree to participate in this focus group, you will be asked to elaborate upon and provide opinions on various points and statements relating to the theme of this research.

- We anticipate that your total involvement will take approximately an hour.

- During the research you are free to withdraw, without any penalty, at any point before the focus group session has commenced.

Privacy and Confidentiality

- We may keep data collected through this focus groups for up to five years

- You will never be identified in my research project or in any other presentation or publication. The information you provide will be coded by number only.

- In accordance with the requirements of some scientific journals and organisations, your coded and confidential data we collect may be shared with other competent researchers.

- Your coded data may be used in other, related studies.

- A copy of the coded and confidential data will remain in the custody of Christopher Aitken for up to five years

What happens to the information that you provide?

- The data you provide may be used for one or more of the following purposes:

- The overall findings may be submitted for publication in a scientific journal, or presented at scientific conferences.

- The overall findings may form part of a Masters thesis that will be submitted for assessment.

If you have any further questions regarding this study please contact me (Christopher Aitken) at the above contact address. 


\section{Focus Group Consent Form}

\section{Statement of consent for participation in focus group research}

I have read the information about this research and any questions I wanted to ask have been answered to my satisfaction.

I am aware of and understand that:

- This research is for the completion of a Masters of Environmental Studies degree at Victoria University of Wellington

- $\quad$ Data from this research may be kept up to 5 years

- $\quad$ All data will be confidential, coded and kept secure

- $\quad$ Data may be released to other researchers upon request

I agree to participate in this research. I understand that I can withdraw my consent at any time, without penalty, prior to the commencement of discussion.

Name:

Signature:

Date: 


\section{Appendix 2- Questionnaire Documents Questionnaire Information Sheet}

TE WHARE WĀNANGA O TE ŪPOKO O TE IKA A MĀUI

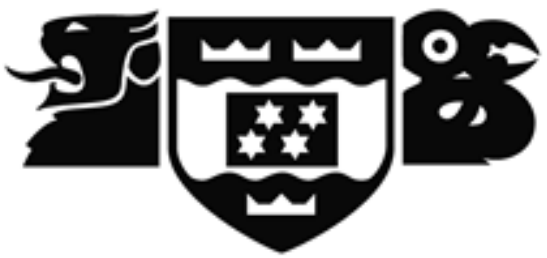

Information Sheet for Survey Participants

Christopher Aitken

MEnvStud Student

aitkenchri@student.vuw.ac.nz
Ralph Chapman

Associate Professor

ralph.chapman@vuw.ac.nz
John McClure

Associate Professor

john.mcclure@vuw.ac.nz 463-6047

What is the purpose of this research?

- This research will enable us to examine the role of powerlessness in influencing people's actions about climate change

Who is conducting the research?

- Christopher Aitken in the School of Geography, Environment and Earth Sciences. Supervised by Associate Professor Ralph Chapman of the School of Geography, Environment and Earth Sciences and Associate Professor John McClure of the School of Psychology. This research has been approved by the University ethics committee

What is involved if you agree to participate?

- If you agree to participate in this study you will fill out a short questionnaire where you give your ratings of considerations about possible action on climate change

- We anticipate that your total involvement will take no more than 5 minutes.

- During the research you are free to withdraw, without any penalty, at any point before your data have been collected.

Privacy and Confidentiality

- We may keep data collected through this survey for up to five years

- You will never be identified in my research project or in any other presentation or publication. The information you provide will be coded by number only.

- In accordance with the requirements of some scientific journals and organisations, your coded and anonymous data we collect may be shared with other competent researchers.

- Your coded data may be used in other, related studies.

- A copy of the coded and anonymous data will remain in the custody of Christopher Aitken for up to five years

What happens to the information that you provide?

- The data you provide may be used for one or more of the following purposes:

- The overall findings may be submitted for publication in a scientific journal, or presented at scientific conferences.

- The overall findings may form part of a Masters thesis that will be submitted for assessment.

If you have any further questions regarding this study please contact me (Christopher Aitken) at the above contact address. 
Questionnaire

TE WHARE WĀNANGA O TE ŪPOKO O TE IKA A MĀUI

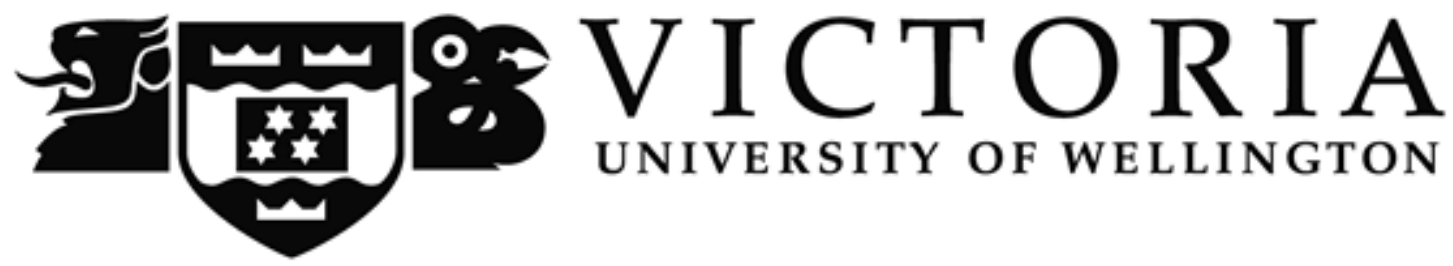

\section{Introduction}

Climate change which includes global warming is widely seen as a significant issue today. We are often asked to make changes in our lives that will lessen climate change. However there may be reasons leading us to choose not to make changes. This questionnaire asks about your views on these choices.

Completion of this survey indicates consent for data from the questionnaire to be included in analysis.

For all questions except question 5 please mark with an $\mathrm{X}$ on the line to indicate your opinion.

1. How well informed do you consider yourself on the issue of climate change?

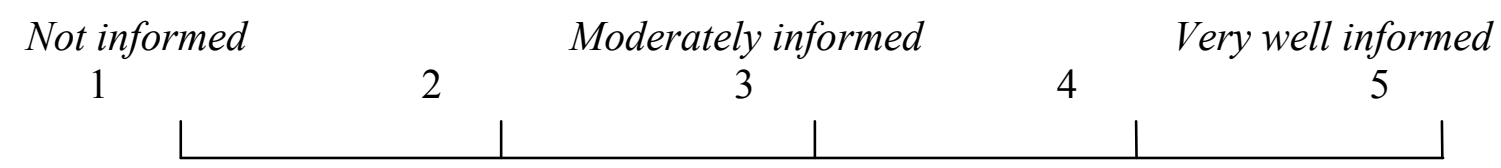

2. To what extent do you believe human activity is contributing to climate change?

Not at all

1
3
A lot

5

3. How severe do you consider the problem of climate change?

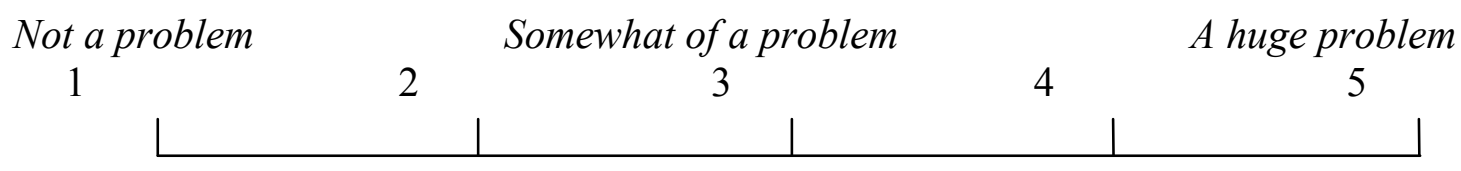

4. How soon should climate change be dealt with?

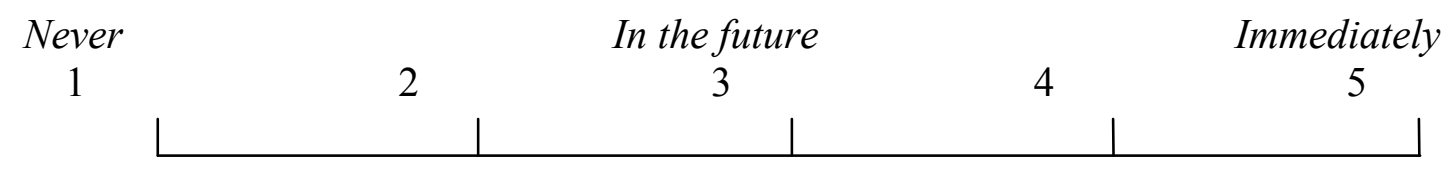


5. Have you changed your actions, at least partly, due to consideration of climate change? Yes/No (Circle One) If you answer No please go to question 7.

6. How much has climate change been a factor in changing your actions? A minor factor

1

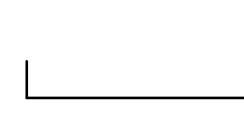

2

3

A major factor

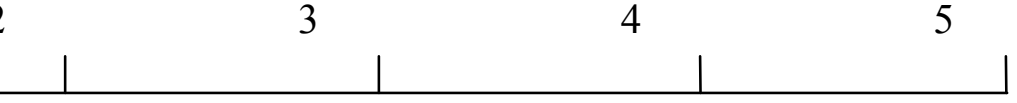

How influential have the following factors been in shaping your own decisions about actions that might affect climate change?

7. The monetary cost of changing my actions

Not influential

1

2

3

Very influential

\begin{tabular}{|l|l|l|}
\hline & \\
\hline
\end{tabular}

8. The availability of options for change

Not influential

1

2

3

Very influential

\begin{tabular}{|l|l|l|l|l|}
2 & 3 & 4 & 5 \\
& & & & \\
\hline
\end{tabular}

9. The inconvenience of options for change Not influential

1

2

3

Very influential

$4 \quad 5$

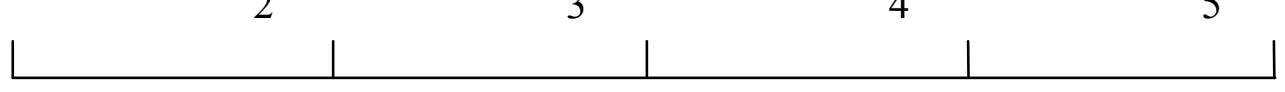

10. Fitting changes in with family and others

Not influential

1

2

3

Very influential

45

\begin{tabular}{|l|l|l|} 
& & \\
\hline
\end{tabular}

11. Lack of knowledge about possible changes I can make Not influential

1

2

3

Very influential

4

12. Uncertainty about the best option to contribute to reducing climate change Not influential

1

2

3

Very influential

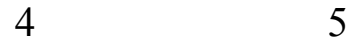


How influential have the following factors been in shaping your own decisions about actions that might affect climate change?

13. Uncertainty as to whether climate change is a significant problem Not influential

1

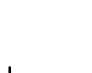

2

3

Very influential

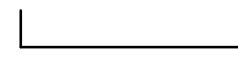

14. The feeling that climate change is too big for my actions to have an impact Not influential

1

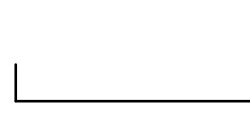

2

3

Very influential

45

15. The feeling that my actions will not affect the outcome of climate change Not influential

1

2

3

Very influential

\begin{tabular}{|l|l|l|l|l|}
3 & 4 & 5 \\
& & & & 5
\end{tabular}

16. The feeling that my contribution is just a drop in the ocean and so is insignificant Not influential

1

2

3

Very influential

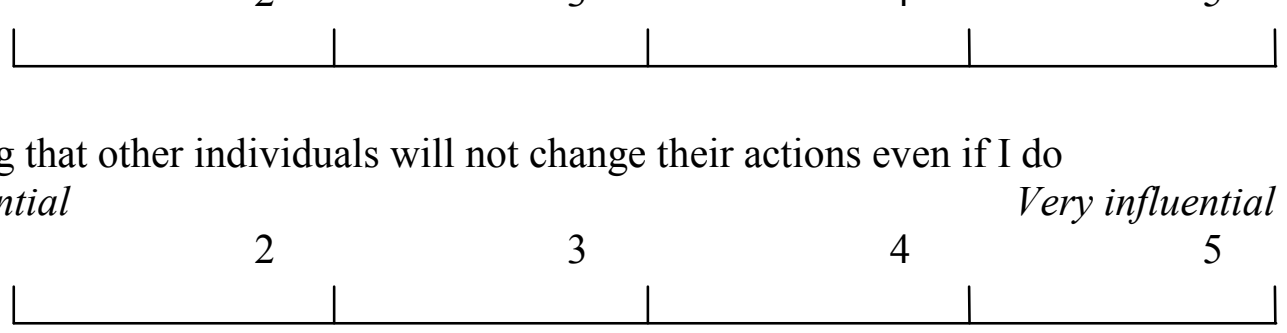

17. Feeling that other individuals will not change their actions even if I do Not influential

1

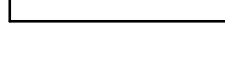

18. Unfairness associated with bearing the cost of change whilst others do not Not influential 1

2

3

Very influential

\begin{tabular}{|l|l|l|l|l|}
2 & 3 & 4 & 5 \\
& & & & 5
\end{tabular}

19. Other countries or people not taking equivalent action currently

Not influential

1

2

3

Very influential

\begin{tabular}{|l|l|l|l|l|}
3 & 4 & 5 \\
& & & & 5 \\
\hline
\end{tabular}

20. Looking foolish due to being the only one to change actions Not influential

1

2

3

Very influential

45 
21. Please indicate your age and gender

Under 20

$20-29$

$30-39$

$40-49$

$50-59$

$60+$

Male/Female

22. What is your highest level of education?

No Qualification

High School Qualification

Tertiary Degree

Tertiary Other

23. If you don't mind, please indicate your individual income?

$\$ 0$ - $\$ 25,000$

$\$ 25,001-\$ 50,000$

$\$ 50,001-\$ 75,000$

$\$ 75,001+$ 


\section{References}

Anderson, C. (2003). The psychology of doing nothing: Forms of decision avoidance result from reason and emotion. Psychological Bulletin, 129(1), 139-167.

Barr, S., \& Gilg, A. (2007). A Conceptual Framework for Understanding and Analyzing Attitudes Towards Environmental Behaviour. Geografiska Annaler: Series B, Human Geography, 89(4), 361-379.

Barr, S., Gilg, A., \& Ford, N. (2001). A conceptual framework for understanding and analysing attitudes towards household-waste management. Environment and Planning A, 33(11), 2025-2048.

Biel, A., \& Gärling, T. (1995). The role of uncertainty in resource dilemmas. Journal of Environmental Psychology, 15(3), 221-233.

Binswanger, M. (2001). Technological progress and sustainable development: what about the rebound effect? Ecological Economics, 36(1), 119-132.

Bixenstine, V. E., Levitt, C. A., \& Wilson, K. V. (1966). Collaboration Among 6 Persons in a Prisoners Dilemma Game. Journal of Conflict Resolution, 10(4), 488-496.

Bord, R. J., O'Connor, R. E., \& Fischer, A. (2000). In what sense does the public need to understand global climate change? Public Understanding of Science, 9(3), 205-218.

Boykoff, M., \& Boykoff, J. (2004). Balance as bias:global warming and the US prestige press. Global Environmental Change Part A, 14(2), 125-136.

Brechin, S. (2003). Comparative public opinion and knowledge on global climatic change and the Kyoto protocol: The U.S. versus the world? The International Journal of Sociology and Social Policy, 23(10), 106-134.

Brookes, L. (1990). The greenhouse effect: the fallacies in the energy efficiency solution. Energy Policy, 18(2), 199-201.

Brown, M. A., Levine, M. D., Romm, J. P., Rosenfeld, A. H., \& Koomey, J. G. (1998). Engineering-Economic Studies of Energy Technologies to Reduce Greenhouse Gas Emissions: Opportunities and Challenges. Annual Review of Energy and the Environment, 23(1), 287-385.

Bruckner, E. (1890). Klimaschwankungen seit 1700 In Nebst Bemerkungen uber die Klimaschwankungen der Diluvialzeit. Vienna: Holzen.

Bulkeley, H. (2000). Common knowledge? Public understanding of climate change in Newcastle, Australia. Public Understanding of Science, 9(3), 313-333.

Burtraw, D., Evans, D. A., Krupnick, A., Palmer, K., \& Toth, R. (2005). Economics of pollution trading for SO2 and NOx. Annual Review of Environment and Resources, 30, 253-289.

Clark, K., \& Sefton, M. (2001). The Sequential Prisoner's Dilemma: Evidence on Reciprocation. The Economic Journal, 111(468), 51-68.

Cohen, D., \& Nisbett, R. E. (1998). Are there differences in fatalism between rural Southerners and Midwesterners? Journal of Applied Social Psychology, 28(23), 2181-2195.

Corraliza, J. A., \& Berenguer, J. (2000). Environmental Values, Beliefs, and Actions: A Situational Approach. Environment and Behavior, 32(6), 832-848.

Cremer, D. D., \& Dijk, E. v. (2002). Perceived Criticality and Contributions in Public Good Dilemmas. Group Processes \& Intergroup Relations, 5(4), 319-332.

Cremer, D. D., \& Dijk, E. v. (2003). Fairness and Ethics in Social Decision Making Social Justice Research, 16(3), 191-194.

Creswell, J., \& Clark, V. (2007). Designing and Conducting Mixed Method Research. Thousand Oaks: Sage. 
Dawes, R. M., \& Messick, D. M. (2000). Social Dilemmas. International Journal of Psychology, 35(2), 111-116.

Desai, M. (2003). Public Goods: A Historical Perspective. In I. Kaul, P. Conceicao, K. L. Goulven \& R. Mendoza (Eds.), Providing Global Public Goods: Managing Globalization (pp. 63-77). New York: Oxford University Press.

Dunlap, R. E., Van Liere, K. D., Mertig, A. G., \& Jones, R. E. (1992, Aug). Measuring endorsement of the new ecological paradigm: A revised NEP scale. Paper presented at the Meeting of the Rural-Sociological-Society, University Pk, Pennsylvania.

Eden, S. E. (1993). Individual Environmental Responsibility and its role in Public Environmentalism. Environment and Planning A, 25(12), 1743-1758.

Eliot, I., Finlayson, C. M., \& Waterman, P. (1999). Predicted climate change, sea-level rise and wetland management in the Australian wet-dry tropics. Wetlands Ecology and Management, 7(1), 63-81.

EPA. (2008). Human-Related Sources and Sinks of Carbon Dioxide. Retrieved 26 January, 2009, from http://www.epa.gov/climatechange/emissions/co2 human.html

Fearnside, P., \& Laurance, W. (2004). Tropical Deforestation and Greenhouse-Gas Emissions. Ecological Applications, 14(4), 982-986.

Fehr, E., \& Schmidt, K. M. (1999). A Theory Of Fairness, Competition, and Cooperation. Quarterly Journal of Economics, 114(3), 817-868.

Fox, J., \& Guyer, M. (1978). Public Choice and Cooperation in N-Person Prisoners-Dilemma. Journal of Conflict Resolution, 22(3), 469-481.

Futerra. (2004). Public Understanding of Climate Change. London: Futerra.

Gachter, S., \& Thoni, C. (2004, Aug 20-24). Social learning and voluntary cooperation among like-minded people. Paper presented at the 19th Annual Congress of the EuropeanEconomic-Association, Madrid, SPAIN.

Garson, G. (2002). Guide to Writing Empirical Papers, Theses and Dissertations. New York: Marcel Dekker.

Goodwin, R., \& Allen, P. (2000). Democracy and fatalism in the former Soviet Union. Journal of Applied Social Psychology, 30(12), 2558-2574.

Green-Demers, I., Pelletier, L., \& Menard, S. (1997). The Impact of Behavioural Difficulty on the Saliency of the Association Between Self-Determined Motivation and Environmental Behaviours. Canadian Journal of Behavioural Science, 29(3), 157-166.

Greening, L., Greene, D. L., \& Difiglio, C. (2000). Energy efficiency and consumption -- the rebound effect -- a survey. Energy Policy, 28(6-7), 389-401.

Greenspan, A. (2007). The Age of Turbulence: Adventures in a New World. New York: Penguin Press.

Grothmann, T., \& Patt, A. (2005). Adaptive capacity and human cognition: The process of individual adaptation to climate change. Global Environmental Change-Human and Policy Dimensions, 15(3), 199-213.

Haller, M., \& Hadler, M. (2008). Dispositions to act in favor of the environment: Fatalism and readiness to make sacrifices in a cross-national perspective. Sociological Forum, 23(2), 281-311.

Hansen, J., Holm, L., Frewer, L., Robinson, P., \& Sandøe, P. (2003). Beyond the knowledge deficit: recent research into lay and expert attitudes to food risks. Appetite, 41(2), 111-121.

Harré, N. (2007). The Psychological Challenge of Climate Change. In N. Harré \& Q. Atkinson (Eds.), Carbon Neutral by 2020. Nelson: Craig Potton Publishing. 
Harrison, C. M., Burgess, J., \& Filius, P. (1996). Rationalizing environmental responsibilities : A comparison of lay publics in the UK and the Netherlands. Global Environmental Change Part A, 6(3), 215-234.

He, K., Huo, H., Zhang, Q., He, D., An, F., Wang, M., et al. (2005). Oil consumption and CO2 emissions in China's road transport: current status, future trends, and policy implications. Energy Policy, 33(12), 1499-1507.

Hegerl, G., Zwiers, F., Braconnot, P., Gillert, N., Luo, Y., Orsini, J., et al. (2007). 2007: Understanding and Attributing Climate Change. In S. Solomon, D. Qin, M. Manning, Z. Chen, M. Marquis, K. Averyt, M. Tignor \& H. Miller (Eds.), Climate Change 2007: The Physical Science Basis. Contribution of Working Group I to the Fourth Assessment Report of the Intergovernmental Panel on Climate Change. Cambridge, United Kingdom: Cambridge University Press.

Hemmelskamp, J. (1997). Environmental policy instruments and their effects on innovation. European Planning Studies, 5(2), 177.

Hinchliffe, S. (1996). Helping the earth begins at home - The social construction of socioenvironmental responsibilities. Global Environmental Change-Human and Policy Dimensions, 6(1), 53-62.

Hindriks, J., \& Pancs, R. (2002). Free Riding on Altruism and Group Size. Journal of Public Economic Theory, 4(3), 335-346.

Isaac, M., McCue, K., \& Plott, C. (1985). Public goods provision in an experimental environment. Journal of Public Economics, 26(1), 51-74.

Isaac, M., \& Walker, J. (1988). Group Size Effects in Public Goods Provision: The Voluntary Contributions Mechanism. Quarterly Journal of Economics, 103(1), 179-199.

Isaac, M., \& Walker, J. (1988). Group Size Effects in Public Goods Provision: The Voluntary Contributions Mechanism. Quarterly Journal of Economics, 103(1), 179-199.

Jackson, T. (2005). Motivating Sustainable Consumption. Guildford: Sustainable Development Research Network.

Jacques, P. J., Dunlap, R. E., \& Freeman, M. (2008). The organisation of denial: Conservative think tanks and environmental scepticism. Environmental Politics, 17(3), 349-385.

Kaplan, S. (2000). Human nature and environmentally responsible behavior. Journal of Social Issues, 56(3), 491-508.

Kellstedt, P. M., Zahran, S., \& Vedlitz, A. (2008). Personal efficacy, the information environment, and attitudes toward global warming and climate change in the United States. Risk Analysis, 28(1), 113-126.

Kerr, N. (1996). "Does My Contribution Really Matter?": Efficacy in Social Dilemmas. European Review of Social Psychology, 7, 209-240.

Kerr, N., \& Kaufman-Gilliland, C. (1997). "And besides, I probably couldn't have made a difference anyway": Justification of social dilemma defection via perceived selfinefficacy. Journal of Experimental Social Psychology, 33(3), 211-230.

Keser, C., \& Winden, F. v. (2000). Conditional Cooperation and Voluntary Contributions to Public Goods. Scandinavian Journal of Economics, 102(1), 23-39.

Kortenkamp, K. V., \& Moore, C. F. (2006). Time, uncertainty, and individual differences in decisions to cooperate in resource dilemmas. Personality and Social Psychology Bulletin, 32(5), 603-615.

Laury, S. K., Walker, J. M., \& Williams, A. W. (1999). The voluntary provision of a pure public good with diminishing marginal returns. Public Choice, 99(1-2), 139-160. 
Leiserowitz, A. (2006). Climate Change Risk Perception and Policy Preferences: The Role of Affect, Imagery, and Values. Climatic Change, 77(1), 45-72.

Lorenzoni, I., Nicholson-Cole, S., \& Whitmarsh, L. (2007). Barriers perceived to engaging with climate change among the UK public and their policy implications. Global Environmental Change-Human and Policy Dimensions, 17(3-4), 445-459.

Lucas, K., Brooks, M., Darnton, A., \& Jones, J. E. (2008). Promoting pro-environmental behaviour: existing evidence and policy implications. Environmental Science \& Policy, 11(5), 456-466.

Ludwig, D. (2001). The Era of Management Is Over. Ecosystems, 4(8), 758-764.

Marland, G., Boden, T., \& Andres, R. (2007). Global, Regional, and National CO2 Emissions. In Trends: A Compendium of Data on Global Change. Oak Ridge, Tenn., U.S.A. : Carbon Dioxide Information Analysis Center.

McClure, J., Sibley, C., \& Sutton, R. (2007). Listening to Reporters or Engineers? How InstanceBased Messages About Building Design Affect Earthquake Fatalism. Journal of Applied Social Psychology, 37(9), 1956-1973.

McKie, R. (2009, 18 January). President 'has four years to save Earth'. The Guardian.

Milinski, M., Semmann, D., Krambeck, H. J., \& Marotzke, J. (2006). Stabilizing the Earth's climate is not a losing game: Supporting evidence from public goods experiments. Proceedings of the National Academy of Sciences of the United States of America, 103(11), 3994-3998.

Ministry-for-Environment. (2008). Questions and answers about the emissions trading scheme. Retrieved. from http://www.climatechange.govt.nz/emissions-trading-scheme/questionsand-answers.html\#activities.

Monbiot, G. (2006). Heat : how to stop the planet burning London: Allen Lane.

Moser, S. C., \& Dilling, L. (2004). Making climate hot: communicating the urgency and challenge of global climate change.(BEYOND KYOTO). Environment, 46(10), 32(15).

Moss, D. (2009). Onset of global warming visible. Arizona Daily Sun.

Müller, M., Kals, E., \& Maes, J. (2008). Fairness, Self-Interest, and Cooperation in a Real-Life Conflict. Journal of Applied Social Psychology, 38(3), 684-704.

N.O.A.A. (2006). Scientific Assessment of Ozone Depletion: 2006. Retrieved. from.

Nicholson-Cole, S. A. (2005). Representing climate change futures: a critique on the use of images for visual communication. Computers, Environment and Urban Systems, 29(3), 255-273.

Niemeyer, S., Petts, J., \& Hobson, K. (2005). Rapid Climate Change and Society: Assessing Responses and Thresholds. Risk Analysis, 25(6), 1443-1456.

Norgaard, K. M. (2006). "People want to protect themselves a little bit": Emotions, denial, and social movement nonparticipation. Sociological Inquiry, 76(3), 372-396.

Olson, M. (1971). The Logic of Collective Action. New York: Schocken.

Oreskes, N. (2004). Beyond the ivory tower - The scientific consensus on climate change. Science, 306(5702), 1686-1686.

Ostrom, V., \& Ostrom, E. (1999). Public Goods and Public Choice. In M. D. McGinnis (Ed.), Polycentricity and Local Public Economies (pp. 75-106). Indiana: University of Michigan Press.

Pfeiffer, T., \& Nowak, M. A. (2006). Climate change: All in the game. Nature, 441(7093), 583584. 
Pichert, D., \& Katsikopoulos, K. V. (2008). Green defaults: Information presentation and proenvironmental behaviour. Journal of Environmental Psychology, 28(1), 63-73.

Potter, E., \& Oster, C. (2008). Communicating climate change: Public responsiveness and matters of concern. Media International Australia(127), 116-126.

Rittel, H. W. J., \& Webber, M. M. (1973). Dilemmas in a general theory of planning. Policy Sciences, 4(2), 155-169.

Romm, J. (2008). Cleaning up on carbon. Nature(0807), 85-87.

Schipper, L., \& Grubb, M. (2000). On the rebound? Feedback between energy intensities and energy uses in IEA countries. Energy Policy, 28(6-7), 367-388.

Schwartz, S. H., \& Howard, J. A. (1981). A Normative Decision-Making Model of Altruism. In J. P. Rushton \& R. M. Sorrentino (Eds.), Altruism and Helping Behaviour: Social, Personality and Developmental Perspectives (pp. 189-211). Hillsdale: Lawrence Erlbaum Assocates.

Seijts, G. H., \& Latham, G. P. (2000). The effects of goal setting and group size on performance in a social dilemma. Canadian Journal of Behavioural Science-Revue Canadienne Des Sciences Du Comportement, 32(2), 104-116.

Semenza, J. C., Hall, D. E., Wilson, D. J., Bontempo, B. D., Sailor, D. J., \& George, L. A. (2008). Public Perception of Climate Change Voluntary Mitigation and Barriers to Behavior Change. American Journal of Preventive Medicine, 35(5), 479-487.

Sims, R., Rogner, H., \& Gregory, K. (2003). Carbon emission and mitigation cost comparisons between fossil fuel, nuclear and renewable energy resources for electricity generation. Energy Policy, 31(13), 1315-1326.

Solomon, S., Plattner, G. K., Knutti, R., \& Friedlingstein, P. (2009). Irreversible climate change due to carbon dioxide emissions. Proceedings of the National Academy of Sciences of the United States of America, 106(6), 1704-1709.

Stanbridge, K., Lyons, G., \& Farthing, S. (2004). Travel behaviour change and residential relocation. Bristol: University of West England.

StatsNZ. (2006a). Census Data. Retrieved 24th September, 2008, from http://www.stats.govt.nz/census/census-outputs/quickstats/default.htm

StatsNZ. (2006b). Census Data. Retrieved 16th December, 2008, from http://www.stats.govt.nz/census/census-outputs/quickstats/default.htm

Stauffer, N. (2008). Carbon emissions trading in Europe: Lessons to be learned. Retrieved 30 September, 2008, from http://web.mit.edu/mitei/research/spotlights/europe-carbon.html

Stehr, N. (1997). Trust and climate. Climate Research, 8(3), 163-169.

Stern, P. (1992). Psychological Dimensions of Global Environmental-Change. Annual Review of Psychology, 43, 269-302.

Stern, P. (1999). Information, Incentives, and Proenvironmental Consumer Behavior. Journal of Consumer Policy, 22(4), 461-478.

Stern, P. (2000). Toward a coherent theory of environmentally significant behavior. Journal of Social Issues, 56(3), 407-424.

Stoll-Kleemann, S., O'Riordan, T., \& Jaeger, C. C. (2001). The psychology of denial concerning climate mitigation measures: evidence from Swiss focus groups. Global Environmental Change-Human and Policy Dimensions, 11(2), 107-117.

Strauss, A., \& Corbin, J. (1990). Basics of Qualitative Research - Grounded Theory Procedures and Techniques. Newbury Park: Sage. 
Tonn, B., Hemrick, A., \& Conrad, F. (2006). Cognitive representations of the future: Survey results. Futures, 38(7), 810-829.

Tsur, Y., \& Zemel, A. (2008). Regulating environmental threats. Environmental \& Resource Economics, 39(3), 297-310.

TVNZ. (2003). Fart tax gone, farmers celebrate. One News.

Ungar, S. (2000). Knowledge, ignorance and the popular culture: climate change versus the ozone hole. Public Understanding of Science, 9(3), 297-312.

Vasi, I. B., \& Macy, M. (2003). The mobilizer's dilemma: Crisis, empowerment, and collective action. Social Forces, 81(3), 979-998.

Wade-Benzoni, K. A., Tenbrunsel, A. E., \& Bazerman, M. H. (1996). Egocentric Interpretations of Fairness in Asymmetric, Environmental Social Dilemmas: Explaining Harvesting Behavior and the Role of Communication. Organizational Behavior and Human Decision Processes, 67(2), 111-126.

Wallace, A. (1994). Ignorance and Poverty are Barriers to Sustainable Agriculture. Communications in Soil Science and Plant Analysis, 25(1-2), 73-75.

Waters, J. R. (1991). Restricted access vs. open access methods of management: toward more effective regulation of fishing effort. (includes bibliography). Marine Fisheries Review, 53(3), p1(10).

Weber, J. M., Kopelman, S., \& Messick, D. M. (2004). A Conceptual Review of Decision Making in Social Dilemmas: Applying a Logic of Appropriateness. Personality \& Social Psychology Review (Lawrence Erlbaum Associates), 8(3), 281-307.

Wood, P. (2009, 18 January). Mid-Atlantic not ready for sea-level rise. The Capital.

Yu, C. C., Au, W. T., \& Chan, K. S. K. (2009). Efficacy = Endowment X Efficiency: Revisiting Efficacy and Endowment Effects in a Public Goods Dilemma. Journal of Personality and Social Psychology, 96(1), 155-169. 